\title{
The $\beta$-hairpin of $40 S$ exit channel protein Rps5/uS7 promotes efficient and accurate translation initiation in vivo
}

\author{
Jyothsna Visweswaraiah, Yvette Pittman, Thomas E Dever*, Alan G Hinnebusch*
}

Laboratory of Gene Regulation and Development, National Institute of Child Health and Human Development, National Institutes of Health, Bethesda, United States

\begin{abstract}
The eukaryotic $43 \mathrm{~S}$ pre-initiation complex bearing tRNA ${ }_{i}{ }^{\text {Met }}$ scans the mRNA leader for an AUG start codon in favorable context. Structural analyses revealed that the $\beta$-hairpin of $40 \mathrm{~S}$ protein Rps5/uS7 protrudes into the 40S mRNA exit-channel, contacting the elF2•GTP•Met-tRNA $A_{i}$ ternary complex (TC) and mRNA context nucleotides; but its importance in AUG selection was unknown. We identified substitutions in $\beta$-strand- 1 and $C$-terminal residues of yeast Rps 5 that reduced bulk initiation, conferred 'leaky-scanning' of AUGs; and lowered initiation fidelity by exacerbating the effect of poor context of the elF1 AUG codon to reduce elF1 abundance. Consistently, the $\beta$-strand-1 substitution greatly destabilized the ' $\mathrm{P}_{\mathrm{IN}}$ ' conformation of TC binding to reconstituted 43S.mRNA complexes in vitro. Other substitutions in $\beta$-hairpin loop residues increased initiation fidelity and destabilized $P_{I N}$ at UUG, but not AUG start codons. We conclude that the Rps 5 $\beta$-hairpin is as crucial as soluble initiation factors for efficient and accurate start codon recognition. DOI: 10.7554/eLife.07939.001
\end{abstract}

*For correspondence: Thomas. Dever@nih.gov (TED); ahinnebusch@nih.gov (AGH)

Competing interests: The authors declare that no competing interests exist.

Funding: See page 19

Received: 05 April 2015

Accepted: 01 July 2015

Published: 02 July 2015

Reviewing editor: Nahum Sonenberg, McGill University, Canada

This is an open-access article free of all copyright, and may be freely reproduced, distributed, transmitted, modified, built upon, or otherwise used by anyone for any lawful purpose. The work is made available under the Creative Commons CCO public domain dedication.

\section{Introduction}

Accurate identification of the translation initiation codon is critical to ensure synthesis of the correct cellular proteins. In eukaryotic cells this process generally occurs by a scanning mechanism, wherein the small (40S) ribosomal subunit first recruits initiator tRNA (Met-tRNA ${ }_{i}$ ) in a ternary complex (TC) with elF2-GTP in a reaction stimulated by elFs $1,1 \mathrm{~A}$, and 3 . The resulting $43 \mathrm{~S}$ pre-initiation complex (PIC) attaches to the mRNA 5' end and scans the 5' UTR for an AUG, using complementarity with the anticodon of Met-tRNA $A_{i}$ to identify the start codon and assemble a 48S PIC. Nucleotides immediately surrounding the AUG, particularly the -3 and +4 positions (referred to below as context nucleotides), also influence start codon selection. During scanning, the GTP bound to elF2 in the TC is hydrolyzed in the 43S PIC in a manner dependent on the GTPase activating protein elF5, but $\mathrm{P}_{\mathrm{i}}$ release is blocked by elF1, which also impedes stable binding of Met-tRNA $A_{i}$ in the $P$ site. Start codon recognition triggers dissociation of elF1 from the 40S subunit, which allows interaction between elF5 and the C-terminal tail (CTT) of elF1A, $P_{i}$ release from elF2-GDP. $P_{i}$, and more stable TC binding in the $P$ site (Figure 1). Subsequent dissociation of elF2-GDP and other elFs from the 48S PIC enables elF5B-catalyzed subunit joining and formation of an $80 \mathrm{~S}$ initiation complex with Met-tRNA $A_{i}$ base-paired to AUG in the $P$ site (reviewed in Hinnebusch, 2014).

elF1 plays a dual role in the scanning mechanism. It promotes an open, scanning-conducive conformation of the PIC (Pestova and Kolupaeva, 2002) to which TC rapidly loads, bound in a state capable of inspecting successive triplets entering the P site (dubbed $\mathrm{P}_{\text {OUT }}$ ) (Passmore et al., 2007; Saini et al., 2010); and it also blocks recognition of near-cognate start codons (e.g., UUG) (Yoon and Donahue, 1992) and AUG codons in poor sequence context (Pestova and Kolupaeva, 2002). Hence, elF1 must dissociate from the 40S subunit (Maag et al., 2005; Cheung et al., 2007) to allow $P_{i}$ release (Algire et al., 2005) and rearrangement to a scanning-incompatible state with Met-tRNA $A_{i}$ base paired 
eLife digest To make a protein, the DNA sequence of a gene is first copied to make an mRNA molecule, which is then translated into a protein by a molecular machine called the ribosome. The first step of translation is known as initiation. Several proteins referred to as initiation factors can bind to the small subunit of the ribosome, which itself is composed of an RNA molecule and numerous proteins, and form a pre-initiation complex (or PIC for short). This complex contains a molecule called initiator tRNA that is specialized for initiation. The PIC then attaches to the mRNA and starts scanning it, searching the sequence for an AUG triplet to serve as the start codon. The sequence immediately surrounding an AUG triplet, known as the context, influences the likelihood of its selection as the start site. When the start codon is recognized by the initiator tRNA in the PIC, the complete ribosome assembles and begins to build the protein. Choosing the correct start codon is crucial to ensure that the correct protein is made from every mRNA in the cell.

The PIC can adopt an 'open' state, which makes it easier to scan the mRNA for the correct start codon and ignore triplets similar in sequence to AUG (like UUG) or AUG triplets in a poor context. Once the correct AUG start codon has been recognized, the PIC changes to a 'closed' state, ceases to scan, and assembles the complete ribosome.

One of the proteins that make up the small ribosomal subunit (called Rps5 in budding yeast) is located near the channel where the mRNA molecule exits the PIC during scanning, and is also thought to be involved in translation initiation. However, the role of Rps5 in recognizing the start codon is poorly understood.

Visweswaraiah et al. have now studied Rps5-in particular, a region of this protein that adopts a hairpin structure that dips into the exit channel—using genetic and biochemical methods. In mutant yeast cells in which the hairpin structure was mutated, translation initiation was diminished at suboptimal start codons-including a UUG start codon and an AUG codon in poor context-thus making translation initiation more accurate.

Visweswaraiah et al. then performed experiments on PICs built from purified components to determine how the Rps5 mutations might affect the assembly and stability of the PIC. The results revealed that mutating the upper region of the Rps5 hairpin destabilized the closed state of the PIC when either an AUG or UUG start codon was present in the mRNA. However, other mutations of the hairpin structure destabilized the closed state of the PIC only at a UUG start codon. In both cases, the mutations made the PIC more likely to remain in the open conformation and continue scanning at incorrect or suboptimal start codons, making it more likely that translation begins at the correct AUG start codon.

These results indicate that the Rps 5 hairpin is crucial for both efficiently and accurately recognizing the start codon to begin translation. This suggests that ribosomal proteins not only contribute to ribosome structure but can actively participate with other initiation factors in choosing the correct start sites for protein synthesis on all mRNAs in the cell.

DOI: 10.7554/eLife.07939.002

with AUG and more tightly bound in the $\mathrm{P}_{\mathrm{IN}}$ conformation (Passmore et al., 2007; Saini et al., 2010). Consistent with this, structural analyses of different PICs reveal that elF1 and elF1A promote rotation of the 40S head relative to the body (Lomakin and Steitz, 2013) (Hussain et al., 2014), which is likely instrumental in TC binding in the POUT conformation, but that elF1 physically obstructs Met-tRNA $A_{i}$ binding in the $P_{\text {IN }}$ state (Rabl et alo, 2011; Lomakin and Steitz, 2013). Accordingly, elF1 is deformed and displaced from its $40 \mathrm{~S}$ location in the open complex during the POUT to $\mathrm{P}_{\mathrm{IN}}$ transition (Hussain et al., 2014). Consequently, mutations that weaken elF1 binding to the $40 S$ subunit reduce the rate of TC loading, while elevating initiation at near-cognate codons or AUGs in poor context, by destabilizing the open/POUT conformation and favoring rearrangement to the closed/ $\mathrm{P}_{\text {IN }}$ state during scanning (Martin-Marcos et al., 2011, 2013). Moreover, decreasing wild-type (WT) elF1 abundance reduces initiation accuracy, whereas overexpressing elF1 suppresses initiation at near cognates or AUGs in poor context (Valasek et al., 2004; Alone et al., 2008; Ivanov et al., 2010; Saini et al., 2010; Martin-Marcos et al., 2011). This tight link between elF1 abundance and initiation accuracy is exploited to autoregulate elF1 expression, as the AUG start codon of the elF1 gene (SUI1 in yeast) occurs in poor context-a feature conserved throughout eukaryotic evolution-and the frequency 


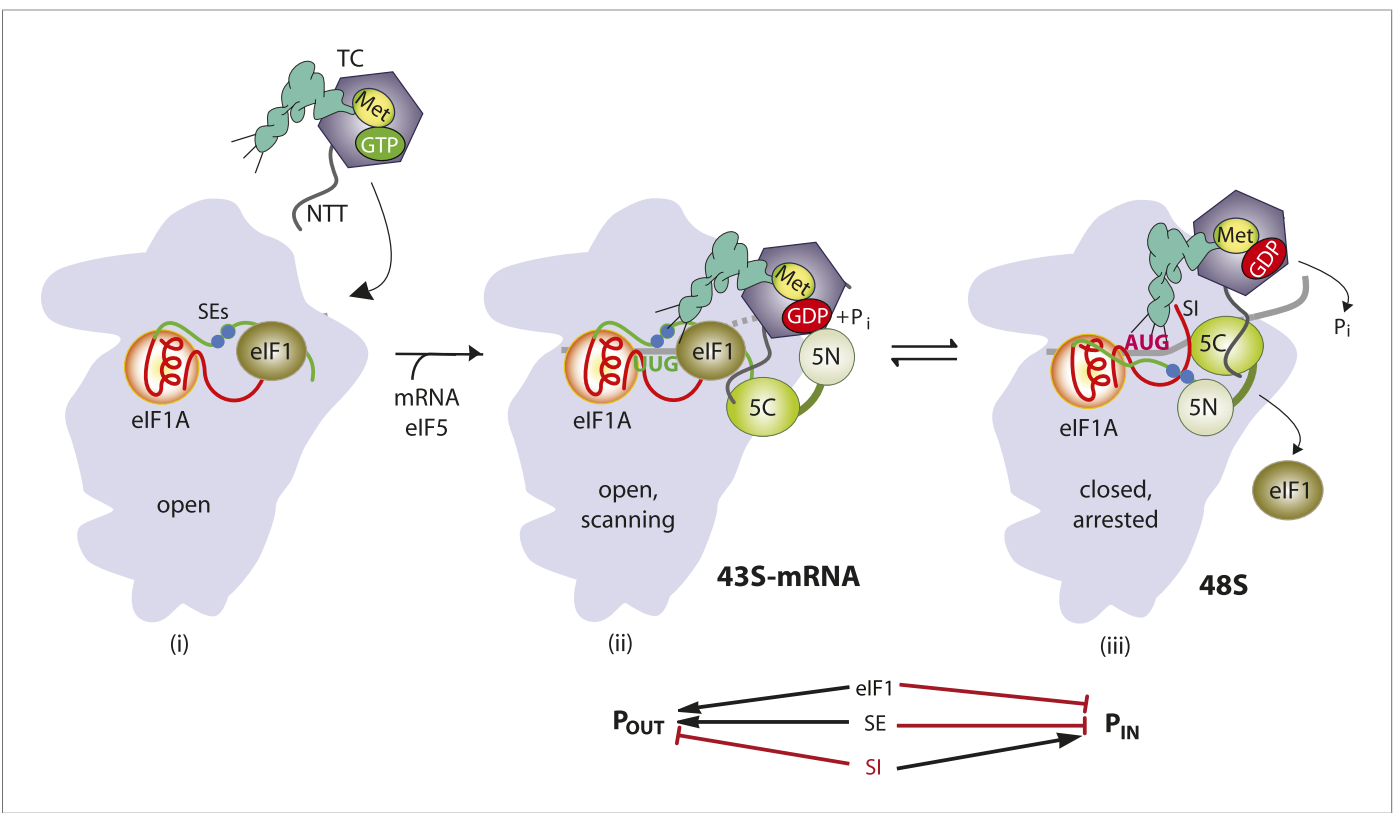

Figure 1. Model describing conformational rearrangements of the PIC during scanning and start codon recognition. Assembly of the PIC, scanning and start codon selection in WT cells. (i) elF1 and the scanning enhancer (SEs) elements in the CTT of elF1A stabilize an open conformation of the 40S subunit to which the TC loads rapidly. (ii) The 43S PIC in the open conformation scans the mRNA for the start codon with Met-tRNA; bound in the Pout state. The GAP domain in the N-terminal domain of elF5 (5N) stimulates GTP hydrolysis by the TC to produce GDP•Pi, but release of $P_{i}$ is blocked. The unstructured NTT of elF2 $\beta$ interacts with elF1 to stabilize elF1 $\bullet 40 S$ association and the open conformation. (iii) On AUG recognition, Met-tRNA $A_{i}$ moves from the POUT to $P_{I N}$ state, clashing with elF1 and the CTT of elF1A. Movement of elF1 and the elF1A CTT away from the P site disrupts elF1's interaction with elF2 $\beta$-NTT, and the latter interacts with the elF5-CTD. elF1 dissociates from the 40S subunit, and the elF5-NTD disengages from elF2 and interacts with the elF1A CTT instead, dependent on the SE elements, thereby facilitating $P_{i}$ release from elF2. The elF5-CTD moves into the position on the $40 \mathrm{~S}$ subunit previously occupied by elF1 and blocks reassociation of elF1. (Below) Arrows summarize that elF1 and the elF1A SE elements promote P $_{\text {OUT }}$ and block transition to the $P_{I N}$ state, whereas the scanning inhibitor (SI) element in the NTT of elF1A stabilizes the $P_{I N}$ state. (Adapted from Hinnebusch and Lorsch, 2012; Nanda et al., 2013).

DOI: 10.7554/eLife.07939.003

of recognizing its own start codon is inversely related to elF1 abundance (Ivanov et al., 2010; Martin-Marcos et al., 2011).

The stability of the codon-anticodon duplex is an important determinant of initiation accuracy, as the rate of the $P_{\text {OUT }}$ to $P_{I N}$ transition and stability of the $P_{I N}$ state are both favored by AUG vs non-AUG start codons (Kolitz et al., 2009). It is possible that favorable context also contributes to the stability of $P_{\text {IN }}$ (Pisarev et al., 2006; Martin-Marcos et al., 2011), but the stimulatory effect of optimum context on initiation rate is not understood at the molecular level. There is evidence that the context nucleotides are recognized by the $\alpha$-subunit of elF2, as replacement of heterotrimeric elF2 with the elF2 $\beta \gamma$ heterodimer reduced the efficiency of AUG recognition and diminished the stimulatory effect of optimum context on 48S PIC assembly in a reconstituted mammalian system (Pisarev et al., 2006). Moreover, crosslinking experiments (Pisarev et al., 2006; Sharifulin et al., 2013) and structural analyses of a mammalian $43 \mathrm{~S}$ PIC (Hashem et al., 2013) and a partial yeast (py48S) PIC (Hussain et al., 2014) indicate that the $\mathrm{N}$-terminal domain (D1) of elF2 $\alpha$ is in proximity to the -3 nucleotide of the mRNA in the exit channel of the $40 \mathrm{~S}$ subunit. These and other studies (Lomakin and Steitz, 2013) revealed that the conserved $\beta$-hairpin of the $40 S$ protein uS7 (Rps5 in yeast) lies in the vicinity of elF2 $\alpha$-D1 and the -3 nucleotide of mRNA in reconstituted 43S/48S PICs (Figure 2A,B); however, functional evidence that elF2 $\alpha$-D1 and the Rps5 $\beta$-hairpin have important roles in start codon recognition in vivo is lacking.

In this report, we establish that the $\beta$-hairpin of Rps5 is critically required for both efficient and accurate translation initiation in vivo. Substituting Glu-144 (E144) in $\beta$-strand 1 of the hairpin, or the proximal C-terminal residue R225 (Figure 2B), confers a marked reduction in the efficiency of AUG 

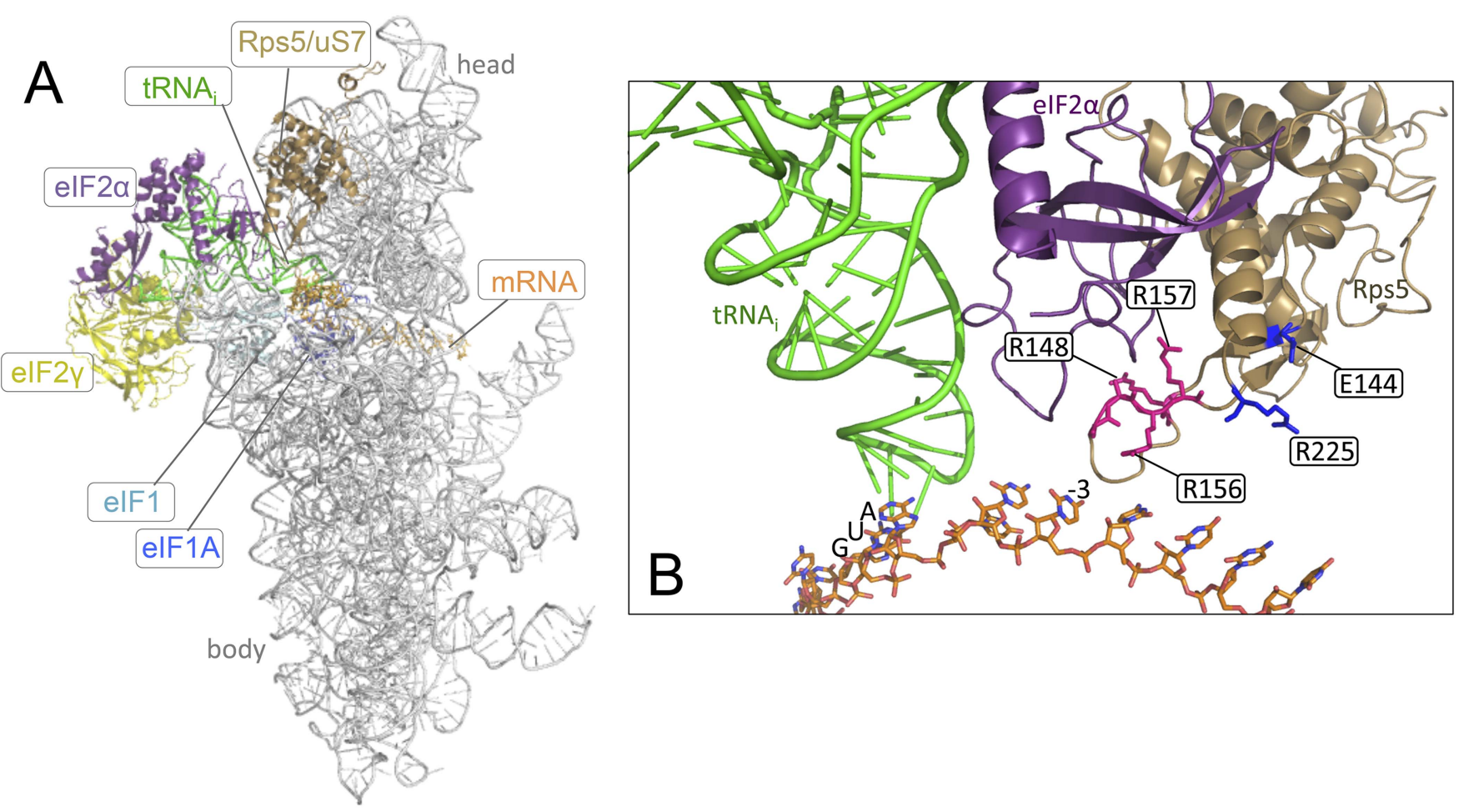

C

Tetrahymena Entamoeba Cryptomonas Leishmania Trypanosoma Mus

Crassostrea Arabidopsis Chlamydomonas Schizosacc. Penicillium Candida Saccharomyces Kluyveromyces

Tetrahymena Entamoeba Cryptomonas Leishmania Trypanosoma Mus

Crassostrea Arabidopsis Chlamydomonas Schizosacc. Penicillium Candida

Saccharomyces Kluyveromyces
KNAFEIIHLVTGRNPLEVFVGAVONAGPREDSTRIGTAGVVRKOAVDVAPMRRVNLAIYF EEAFEIIHLLTEKNPIQVLVDAIINASPREDSTRVGTGGNAKRQAVDVSPLRRINQALYL KDAFELINLITKQNPIQILVDAIVNSGPREDSTKVGSVGSVRRQSVDVSPLRRVNVGIYL KHTLEI IHLLTDENPLQVVVDAVSKGAPREDSTRVGSGGVVRROAVDVSPMRRVNEAIYQ KHTLEIIHLLTDONPLOVVIDAVSKGAPREDSTRVGSGGVVRROAVDVSPMRRVNEAIYL KHAFEI I HLLTGENPLQVLVNAI INSGPREDSTRIGRAGTVRRQAVDVSPLRRVNQA IWL KHAFEI IHLLTGENPLQVLVNAI INSGPREDSTRIGRAGTVRRQAVDVSPLRRVNQAIWL KHAME I I HLLSDLNP IQVI I DA IVNSGPREDATRI GSAGVVRRQAVDISPLRRVNQA I FL KHAFEI INLLTDQNPIQVVVDAI INSGPREDATRIGSAGVVRRQAVDISPLRRVNQAIFL KHAFEI IALLTDQNPLQVLVDAVAACGPREDSTRIGSAGTVRRQAVDVSPLRRVNQALAL AHAFE I I H IMTDQNPLQVAVDA IVNCGPREDSTRIGSQGTVRRQAVDVSPLRRVNQS ISL KHALEI I HVLTEONPIOVVVDAIVNSGAREDSTRIGSSGTVRRQAVDVSPLRRVNOAIAL KHTLDI INVLTDQNPIQVVVDAITNTGPREDTTRVGGGGAARRQAVDVSPLRRVNQAIAL

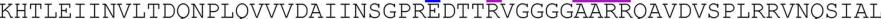

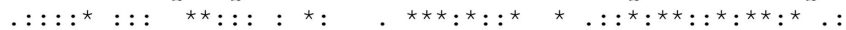

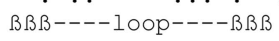

I IKGCRESAFKSMRS IAETLADEI INAEKNNTQSSWA IRKKDE IEKVAKGNR MTMGCRSAAFRNSKTLAECLADEIVNASKSNT-ASFAIKKKEDMERVAKSNR LSMGARNAAFKNTKTIAECLADELVNASRNSS-NSFAIKKKDEIERIAKTNR MCKGAREAAFRNLKSMPECLADEIVNASKGSS-NSYAIKKKDEVERVAKANR MCKGAREAAFRNLKTLPECLADEIVNASKGSS-NSYAIKKKDEVERVAKANR LCTGAREAAFRNIKTIAECLADELINAAKGSS-NSYAIKKKDELERVAKSNR LCTGAREASFRNIKTIAECLADELINAAKGSS-NSHAIKKKDELERVAKSNR LTTGAREAAFRNIKTIAECLADELINAAKGSS-NSYAIKKKDEIERVAKANR ITTGAREAAFRS IKTVAECLADELVNAAKGSS-NSYAIKKKDELERVAKANR ITIGAREAAFRNVKS ISECLAEEI INAAKGSS-NSYAIKKKDELERVAKSNR LTIGAREASFRNIKSIAECLAEELINAAKGSS-NSYAIKKKDELERVAKSNR LTIGAREASFRNIKTIAECLAEELINAAKGSS-TSYAIKKKDELERVAKSNR LTIGAREAAFRNIKTIAETLAEELINAAKGSS-TSYAIKKKDELERVAKSNR LTIGAREAAFRNIKTIAETLAEELINAAKGSS-TSYAIKKKDELERVAKSNR

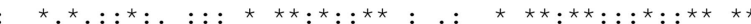

148

154

140

139

139

153

153

156

146

152

160

174

174

176

200

205

191

190

190

204

204

207

197

203

211

225

225

227

Figure 2. Location in the py48S PIC, and sequence conservation, of the Rps5 $\beta$-hairpin loop. (A, B) Depiction of the partial yeast 48S PIC (PDB 3J81) showing Rps5 (gold), mRNA (orange), Met-tRNA (green), elF2 $\alpha$ (purple), elF2 $\gamma$ (yellow), elF1 (cyan) and elF1A (blue). For clarity other ribosomal proteins, eIF2 $\beta$ and putative elF5 densities are not shown. Residues implicated here in AUG recognition are shown with stick side-chains and highlighted (as in panel C) in blue or pink. (C) Alignment of Rps5 sequences from diverse eukaryotes using the Clustal Omega algorithm (http://www.ebi.ac.uk/Tools/msa/ clustalo/). The $\beta$ - hairpin loop is annotated below the alignment and residues implicated in this study in AUG recognition are highlighted in blue or pink and underlined.

DOI: 10.7554/eLife.07939.004 
recognition. This defect exacerbates the effect of poor context at the SUI1 mRNA start codon to reduce elF1 cellular abundance and thereby increase recognition of near-cognate UUG codons as a secondary effect. Analysis in the yeast reconstituted system reveals striking destabilization of the $P_{I N}$ state formed at AUG codons by E144R mutant 40S subunits. Substitutions in the loop portion of the Rps $5 \beta$-hairpin also destabilize the $P_{I N}$ state, but produce this effect selectively for near-cognate UUG start codons, and thereby dampen UUG initiation in vivo. These findings indicate that the Rps 5 $\beta$-hairpin functions on a par with soluble initiation factors, such as elF1, elF1A and elF2, to insure efficient and accurate start codon recognition in eukaryotic cells.

\section{Results}

\section{Substitutions E144R and $R 225 K$ impair translation initiation and start codon selection in vivo}

To examine the role of the Rps5 $\beta$-hairpin in start codon recognition, we introduced single substitutions into 3 residues of $\beta$-strand $1\left({ }_{144} E_{D T}{ }_{146}\right)$ and 8 of the 10 residues in the hairpin loop $\left(_{147} \mathrm{TR}_{148}\right.$ and ${ }_{151} \mathrm{GGGARRQ}_{158}$ ) (Supplementary file 1 ). Residues in the $\beta$-strands, and the loop residues proximal to the $\beta$-strands, are among the most highly conserved in evolution (Figure $2 \mathrm{C}$ ). We also substituted the last four residues of Rps5 $\left({ }_{222} \mathrm{KSNR}_{225}\right)$ in view of their strong conservation and proximity to the $\beta$-hairpin, and because invariant Glu144 in $\beta$-strand 1 (E144) appears to form a saltbridge with C-terminal residue R225 in the yeast 80S ribosome (Ben-Shem et al., 2011) (Figure 2B). Residues were generally substituted with Ala to shorten the side-chain, or with basic or acidic residues to introduce or alter side-chain charge (Supplementary file 1). The mutations were generated in an RPS5 allele under its own promoter on a low-copy plasmid and examined in a yeast strain with WT chromosomal RPS5 under a galactose-inducible promoter $\left(P_{G A L 1}\right)$. Mutant phenotypes were scored following a switch from galactose to glucose, where $P_{G A L 1}-R P S 5$ expression is repressed. Despite strong sequence conservation of many $\beta$-hairpin residues (Figure 2C), only the G151S substitution was lethal and prevented growth on glucose medium; however, several substitutions conferred a slowgrowth ( $\mathrm{Slg}^{-}$) phenotype, including E144R and R225K (Figure 3A, glucose; Supplementary file 1).

To identify effects on fidelity of start codon selection, the mutant strains were assayed for expression of otherwise identical HIS4-lacZ reporters containing an AUG or UUG start codon. Substantial (>twofold) increases in expression of the UUG relative to AUG reporter (UUG:AUG ratio) were observed only for E144R and three different mutations substituting Arg225. Mutations E144R and R225K elevated the UUG:AUG ratio by 5.9- and 3.6-fold, respectively (Figure 3B and Supplementary file 1). To test the importance of the Glu144/Arg225 salt-bridge, we constructed the E144R/R225E double mutant in which the salt-bridge should be reinstated. This strain displayed a $\mathrm{Slg}^{-}$phenotype and increased UUG:AUG ratio similar in magnitude to that of the $R 225 \mathrm{~K}$ mutant but less severe than seen for the E144R strain (Figure $3 A, B$ ). The fact that combining these mutations did not produce more severe phenotypes than those conferred by E144R alone is consistent with the possibility that reinstating the salt-bridge mitigates the effects of the E144R single mutation, with the stipulation that the WT identity of E144 or R225 is needed for robust Rps 5 function. Thus, although the salt-bridge is reinstated, the substitution of one or both residues still impairs growth and initiation fidelity in the double mutant. Additional experiments are needed to establish the importance of the salt bridge for Rps 5 function.

Mutations in various initiation factors are known that elevate the UUG:AUG ratio and restore translation of mutant his4-301 mRNA, which lacks the AUG start codon, by enabling initiation at the third, UUG codon, thereby suppressing histidine auxotrophy and conferring a Sui- (Suppressor of initiation codon mutation) phenotype. However, neither E144R nor R225K suppress the His ${ }^{-}$phenotype of his4-301 to confer the Sui ${ }^{-}$phenotype. Based on previous observations of Sui- mutants, it is possible that the Rps5 substitutions do not elevate the UUG:AUG ratio sufficiently to produce enough his4-301 product for adequate histidine biosynthesis (Dorris et al., 1995; Martin-Marcos et al., 2013). For example, the elF1 mutations sui1-K37A and sui1-R33A increase the UUG:AUG ratio by 4.8- and 7.7-fold, but only the latter suppresses the $\mathrm{His}^{-}$phenotype of his4-301 (Martin-Marcos et al., 2013). Alternatively, the Rps5 mutations could interfere with an unknown aspect of histidine biosynthesis or utilization (Nanda et al., 2009).

Consistent with their Slg- phenotypes, E144R and R225K conferred significant reductions in the polysome:monosome $(\mathrm{P} / \mathrm{M})$ ratio ( $\mathrm{p}$-value $<0.0005)$ (Figure $3 \mathrm{C}$ ), indicating a reduced rate of bulk translation initiation relative to elongation, with the greater reduction conferred by the mutation 


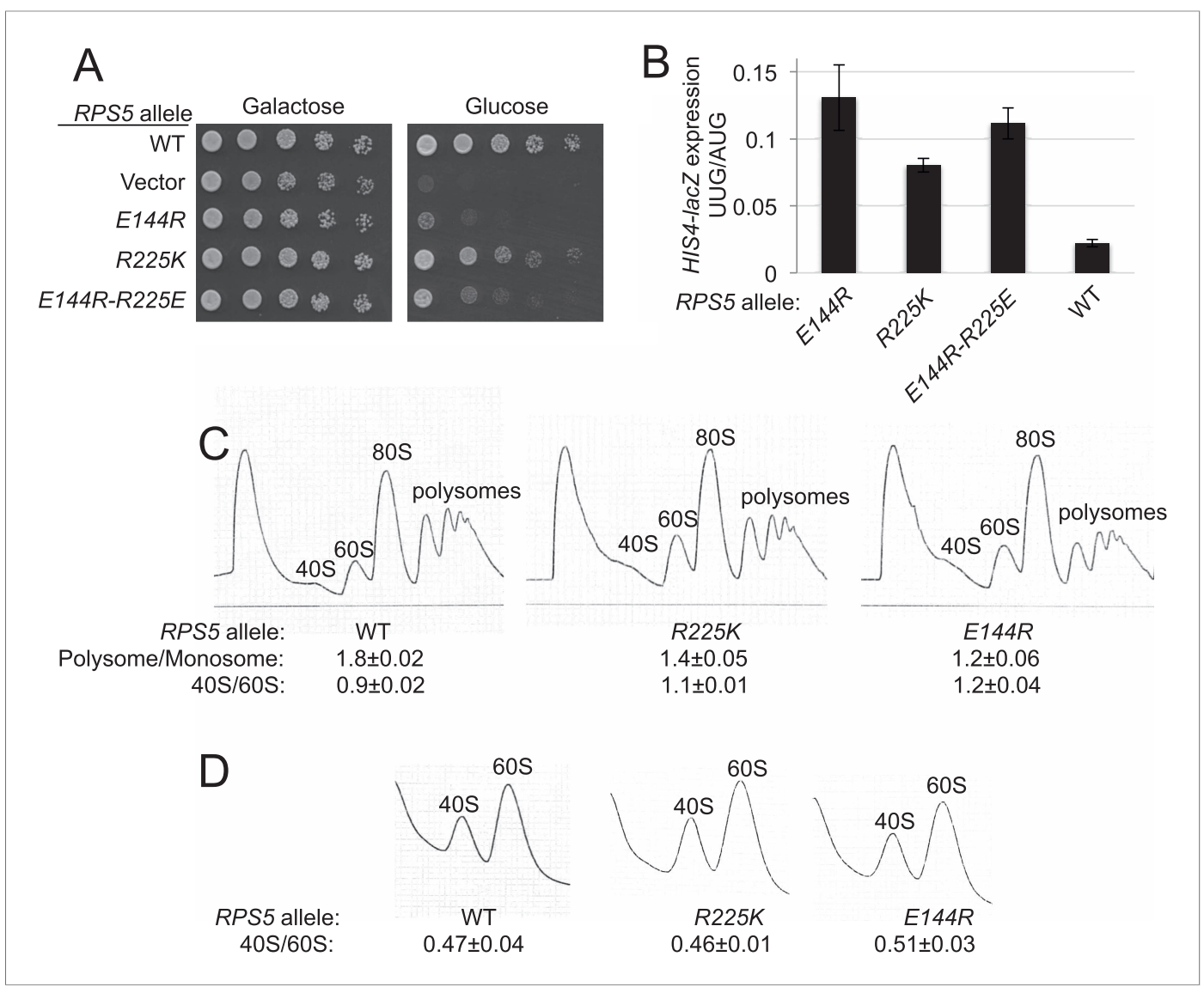

Figure 3. RPS5 mutations $E 144 R$ and R225K impair translation initiation and elevate UUG initiation without reducing $40 S$ subunit abundance in vivo. (A) 10-fold serial dilutions of transformants of $P_{\text {GAL1 }}$-RPS5 his4-301 strain (JVY07) with the indicated plasmid-borne RPS5 alleles were spotted on synthetic medium supplemented with histidine and containing galactose (SGal + His + Ura + Trp) or glucose (SD + His + Ura + Trp) as carbon source and incubated at $30^{\circ} \mathrm{C}$ for 3 days (Glucose) or 4 days (Galactose). (B) Strains from (A) also harboring HIS4-lacZ reporters with AUG or UUG start codons (plasmids p367 and p391, respectively) were cultured in SD + His $+\operatorname{Trp}$ at $30^{\circ} \mathrm{C}$ to $\mathrm{A}_{600}$ of $\sim 1$ and $\beta$-galactosidase specific activities were measured in WCEs in units of nanomoles of o-nitrophenyl- $\beta$-Dgalactopyranoside (ONPG) cleaved per min per mg of total protein. Ratios of mean expression of the UUG and AUG reporters calculated from four transformants are plotted with error bars (indicating S.E.M.s). (C) Strains from (A) were cultured in SD + His + Ura + Trp at $30^{\circ} \mathrm{C}$ to $\mathrm{A}_{600}$ of $\sim 1$, and cycloheximide was added prior to harvesting. WCEs were separated by sucrose density gradient centrifugation and scanned at $254 \mathrm{~nm}$ to yield the tracings shown. Mean Polysome/Monosome and 40S/60S ratios (and S.E.M.s) from four replicates are indicated. Student's t-test indicates that the mean values for polysome/monosome ratio in the RPS5 mutants are reduced significantly from the WT ( $p<0.0005$ ). (D) Similar to (C) but the cultures were not treated with cycloheximide and lysed in buffers without $\mathrm{MgCl}_{2}$ to allow separation of the dissociated ribosomal subunits.

DOI: 10.7554/eLife.07939.005

$(E 144 R)$ with the stronger Slg ${ }^{-}$phenotype (Figure 3A). Neither mutant significantly perturbed the ratio of $40 S$ to $60 S$ subunits (Figure $3 C, D$ ), suggesting that the initiation defects arise from altered $40 S$ function rather than abnormalities in expression of Rps5, 40S biogenesis, or stability of mature 40S subunits. Thus, it appears that $E 144 R$ and $R 225 K$ reduce the function of Rps 5 in stimulating the rate of general translation initiation and promoting accurate start codon selection.

\section{$E 144 R$ and $R 225 K$ elevate UUG initiation indirectly by exacerbating the effect of poor context of the SUI1 start codon and thereby reducing elF1 abundance}

In addition to increasing initiation from near-cognate UUG codons, certain Sui- mutations in elF1, elF1A, and elF2 $\beta$ are known to enhance initiation from AUG codons in poor context. As such, they 
suppress the effects of the suboptimal context of the AUG codon of SUI1 mRNA and increase expression of the encoded elF1 protein (Martin-Marcos et al., 2011). This phenotype is illustrated for the Sui ${ }^{-}$sui1-L96P mutation in Figure 4A (lanes 7, 8 vs 5, 6). However, unlike previously described

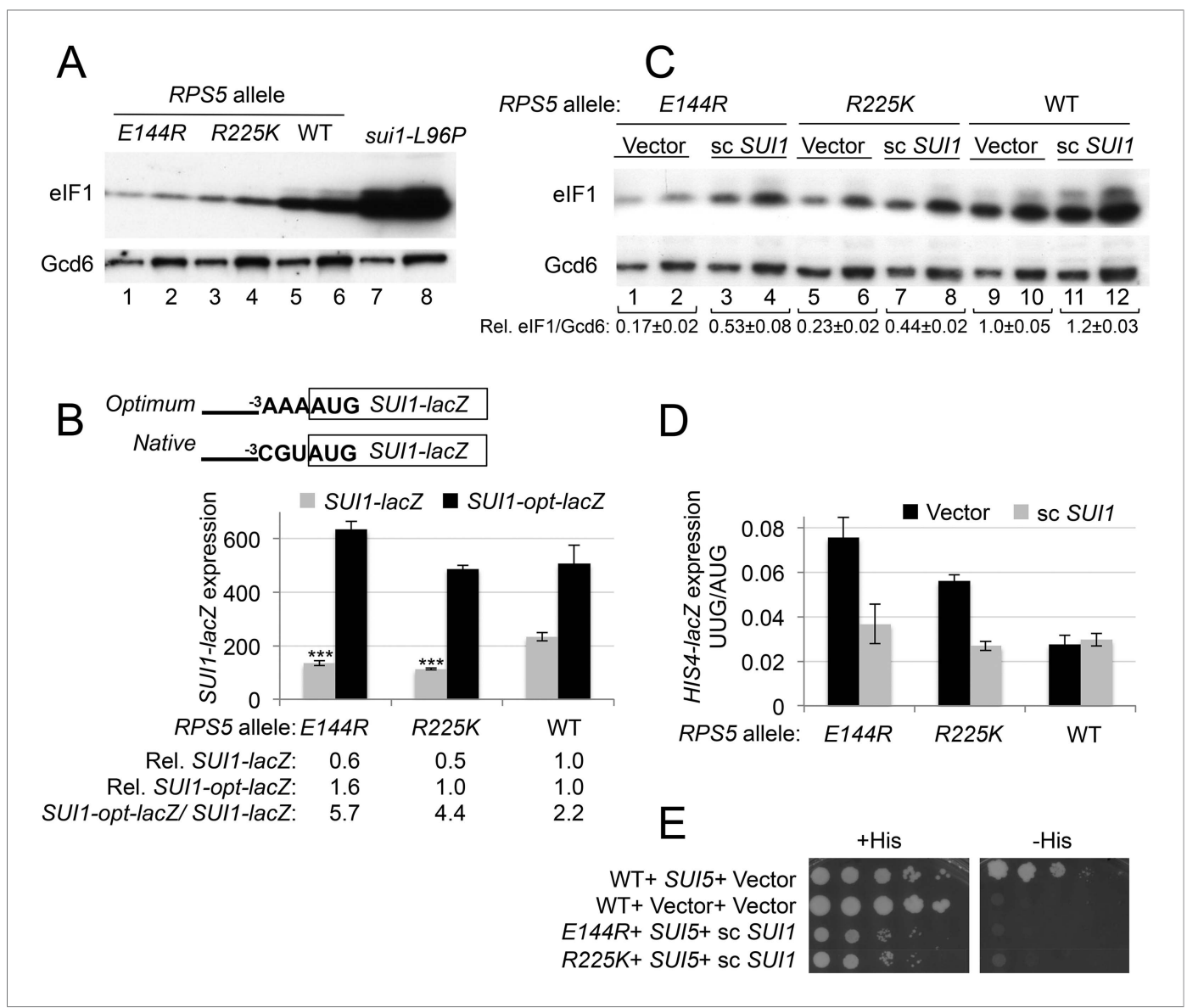

Figure 4. RPS5 mutations E144R and R225K exacerbate poor context at the native SUI1 AUG to reduce elF1 expression and indirectly confer Sui phenotypes, but evoke Ssu' phenotypes when elF1 abundance is boosted. (A) WCEs of strains from Figure 3A, and from sui1-L96P strain H4564, were subjected to Western analysis using antibodies against elF1 or Gcd6 (as loading control). Two amounts of each extract differing by a factor of two were loaded in successive lanes. (B) Strains from Figure 3A also harboring SUI1-lacZ (pPMB24) or SUI1- opt-lacZ (pPMB25) reporters were cultured and assayed for $\beta$-galactosidase activities as described in Figure 3B. Mean expression levels and S.E.M.s from four transformants are plotted, and relative (Rel.) mean expression levels normalized to that of the WT strain are listed below the histogram. Student's $t$-test indicates that the mean values for SUI1-lacZ expression in the RPS5 mutants are reduced significantly from the WT ( $\left.{ }^{\star \star *} p<0.0005\right)$. (C) WCEs of strains from Figure $3 A$ also harboring sc SUI1 plasmid pPMB21 or empty vector were subjected to Western analysis as in (A). Signal intensities were quantified and mean elF1/Gcd6 ratios are listed below the blot with S.E.Ms (D) HIS4-lacZ reporters with AUG or UUG start codons were assayed in strains from (C) as in Figure 3B. (E) his4-301 strains with the indicated WT or mutant RPS5 alleles (from Figure 3A) harboring sc SUI1 plasmid pPMB21, SUI5 plasmid p4281, or empty vectors were spotted on SD plates containing (SD + His) or lacking histidine (SD-His) and incubated for 3 days and 5 days, respectively.

DOI: 10.7554/eLife.07939.006

The following figure supplements are available for figure 4

Figure supplement 1. Increased SUI1 gene dosage partially rescues the Slg phenotype of RPS5 mutations E144R and R225K

DOI: 10.7554/eLife.07939.007

Figure supplement 2. RPS5 mutation E144R confers a Gcd phenotype, derepressing GCN4-lacZ expression with restored elF1 expression.

DOI: 10.7554/eLife.07939.008 
mutations that enhance UUG recognition, rps5-E144R and $-R 225 \mathrm{~K}$ paradoxically decrease elF1 abundance (Figure 4A, lanes $1-4$ vs 5,6 ) to a degree that correlates with their elevated UUG:AUG HIS4-lacZ initiation ratios (Figure 3B). Consistently, E144R and R225K reduce expression of a SUI1-lacZ reporter bearing the native, suboptimal context at the three nucleotides preceding the AUG codon $\left({ }^{-3} \mathrm{CGU}^{-1}\right)$, but not that of a modified $S U I 1_{\text {opt }}$-lacZ reporter with an optimized AUG context $\left({ }^{-3} \mathrm{AAA}^{-1}\right)$ (Figure $\left.4 \mathrm{~B}\right)$. Thus, the rps5 mutations exacerbate the effect of suboptimal context and decrease AUG recognition on WT SUI1 mRNA. The reduction in elF1 abundance implies that the rps5 mutations overcome the autoregulation of elF1 expression, wherein low elF1 levels suppress the effect of poor context at the SUI1 AUG codon to boost elF1 abundance (Ivanov et al., 2010; Martin-Marcos et al., 2011). Accordingly, it appears that the rps5 mutations evoke a pronounced defect in recognition of the native SUI1 AUG codon that prevails even at low cellular concentrations of elF1 that would normally boost SUI1 translation.

Interestingly, the discrimination against native poor context at SUI1 with attendant reduced elF1 expression represents a hyperaccuracy phenotype displayed by known Ssu (Suppressor of Sui ${ }^{-}$) mutations in elF1, elF1A, and elF2 $\beta$, which additionally suppress the elevated UUG:AUG ratio conferred by various Sui ${ }^{-}$mutations (Martin-Marcos et al., 2011). Hence, the fact that rps5-E144R and $-R 225 \mathrm{~K}$ discriminate against poor context at SUI1 but elevate the UUG:AUG ratio seems paradoxical. However, their elevated UUG:AUG ratio (hypoaccurate) phenotype could be explained by the reduced levels of elF1 present in these rps5 mutants (Hinnebusch, 2011). Indeed, we found that increasing the level of WT elF1 by adding an extra plasmid-borne copy of WT SUI1 (Figure 4C, scSUI1 vs Vector transformants) mitigated the Sui ${ }^{-}$phenotypes of both rps5 mutants, reducing their UUG:AUG ratios to essentially WT levels (Figure 4D). Introducing scSUI1 also mitigated their Slg phenotypes, slightly for $-R 225 K$ and substantially for -E144R (Figure 4-figure supplement 1). The resulting rps5/scSUI1 strains exhibit reduced elF1 levels compared to WT cells containing an extra copy of SUI1 (Figure 4C, lanes 3-4 and 7-8 vs 11-12), indicating that the rps5 mutations still exacerbate the effect of poor AUG context at higher levels of elF1 expression. We conclude that the increased recognition of UUG start codons conferred by the rps 5 mutations is an indirect consequence of their reduced expression of elF1.

As noted above, reducing elF1 expression by discriminating against the poor context of the SUI1 AUG codon is a phenotype of known Ssu- (hyperaccuracy) mutants (Martin-Marcos et al., 2011). Since rps 5 mutations also reduced elF1 expression in a context-dependent manner, we next examined whether they exhibit $\mathrm{Ssu}^{-}$phenotypes by testing them for the ability to suppress the dominant Suiphenotype of the SUI5 variant of elF5 (elF5-G31R) (Huang et al., 1997). This test was conducted using the RPS5 mutant strains harboring scSUI1 to compensate for the reduced elF1 expression

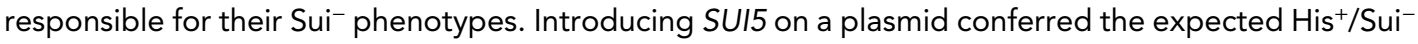
phenotype in the his4-301 strain harboring WT RPS5 and native elF1 levels (Figure 4E, compare row 1 with 2). Importantly, this $\mathrm{His}^{+}$phenotype was eliminated in the corresponding rps5-E144R and $-R 225 \mathrm{~K}$ mutants when elF1 levels were boosted by introduction of scSUI1, as the reduction in growth on -His medium was greater than that seen on +His medium in the rps5/SUI5 mutants vs the RPS5/SUI5 strain (Figure 4E, rows 3-4 vs 1). Suppression of the $\mathrm{His}^{+}$phenotype of SUI5 could arise from defective induction of GCN4 mRNA with attendant impairment of HIS4 transcription (Hinnebusch, 2005); however, at least rps5-E144R does not reduce the expression of a GCN4-lacZ reporter in amino acid starved cells containing an extra copy of SUI1 (Figure 4-figure supplement 2). Hence, similar to known $\mathrm{Ssu}^{-}$mutations in elF1 or elF1A (Martin-Marcos et al., 2011), the rps5-E144R mutation appears to suppress recognition of the UUG start codon of his4-301 mRNA in addition to discriminating against poor context at the SUI1 AUG codon.

\section{$E 144 R$ and $R 225 K$ confer leaky scanning of an upstream AUG start codon}

As noted above, the rps5 mutations decrease recognition of the SUI 1 start codon and suppress UUG initiation when elF1 levels are restored. We next asked whether they also decrease recognition of an upstream AUG codon and allow leaky scanning to the downstream ORF. A GCN4-lacZ reporter was employed with a modified version of upstream ORF1 that is elongated to overlap the GCN4 ORF (el.uORF1). This construct is ideally suited for this query because virtually all scanning ribosomes normally recognize the UORF1 AUG (UAUG-1), and reinitiation at the downstream AUG of the GCN4 main ORF following termination of el.uORF1 translation is almost non-existent, so that translation of 
the main ORF is extremely low (Grant et al., 1994). Remarkably, rps5-E144R confers a dramatic increase in leaky scanning through el.uORF1, elevating GCN4-lacZ expression by 20-fold for the construct containing optimum context $\left({ }^{-3} A A A^{-1}\right)$ at UAUG-1 (Figure 5, row 1, WT vs E144R). This effect is nearly comparable to the $\sim 40$-fold increase in leaky scanning seen in WT cells for the extremely weak uAUG-1 context of ${ }^{-3} \mathrm{UUU}^{-1}$ (Figure 5, WT, row 5 vs row 1). rps5-E144R also evokes a large $\sim 10$-fold increase in leaky scanning for the el.uORF1 construct with the UAUG-1 context of intermediate strength $\left({ }^{-3} \cup A A^{-1}\right)$, but only a fourfold increase with the weakest context of ${ }^{-3} U U^{-1}$ (Figure 5, rows 3 and 5, WT vs E144R). Expression of the construct lacking uAUG-1 is not significantly affected by rps5-E144R (Figure 5, row 7, WT vs E144R), consistent with leaky scanning being the source of elevated GCN4-lacZ expression for the various el.uORF1 constructs. The R225K mutation also increases leaky scanning of $U A$ AUG-1, but to a lesser degree: 3.5 -fold for ${ }^{-3} A A A^{-1}$, 3.3-fold for ${ }^{-3} U A A^{-1}$, and 1.7-fold for ${ }^{-3} U^{-1} U^{-1}$ (Figure 5, rows 1, 3, 5; WT vs R225K). The increases in leaky scanning conferred by the rps 5 mutations were relatively unaffected by the restoration of WT elF1 levels by introducing scSUI1 (Figure 5, rows 2, 4, 6 vs 1, 3, 5, respectively). This was anticipated because the reduced levels of elF1 in the rps5 mutants (lacking scSUI1) would not be expected to reduce UAUG-1 recognition and confer leaky scanning, as decreased elF1 abundance is associated with increased start codon recognition (at least for near-cognate start codons or AUG codons in poor context) (Pestova and Kolupaeva, 2002; Ivanov et al., 2010; Martin-Marcos et al., 2011). We conclude that the rps5 substitutions impair recognition of GCN4 UAUG-1, whether located in perfect or poor surrounding sequence context, to allow increased translation of the downstream GCN4 coding sequences.

\section{Ssu $^{-}$substitution E144R destabilizes the $P_{\text {IN }}$ conformation of the 48S PIC in vitro}

The multiple defects in start codon recognition conferred by rps5-E144R suggest that it destabilizes the $P_{I N}$ state of the 48S PIC. We tested this hypothesis by analyzing the effects of E144R on the equilibrium and rate constants governing TC binding to the $40 S$ subunit in the yeast reconstituted translation system. To this end, we purified $40 \mathrm{~S}$ subunits from rps $5 \Delta:: k a n M X$ deletion strains harboring either plasmid-borne rps5-E144R or WT RPS5 as the only source of Rps5. We began by measuring the affinity of WT TC, assembled with $\left[{ }^{35} \mathrm{~S}\right]-$ Met-tRNA ${ }_{i}$, for mutant or WT 40S subunits in the presence of saturating elF1, elF1A and a model mRNA containing an AUG start codon (mRNA(AUG)), using native gel electrophoresis to separate 40S-bound and unbound fractions of TC. Reactions conducted with increasing concentrations of $40 \mathrm{~S}$ subunits revealed that 43S•mRNA(AUG) complexes assembled with either E144R or WT 40S subunits have relatively high affinities for TC (Figure 6A), with $\mathrm{K}_{d}$ values of $\leq 1 \mathrm{nM}$ (Figure 6E). In the absence of mRNA, the affinities for TC are similar between 43S PICs assembled with mutant or WT $40 \mathrm{~S}$ subunits (Figure 6E); however, the endpoint of the reaction is

\begin{tabular}{|c|c|c|c|c|}
\hline & \multicolumn{4}{|c|}{$\beta$-galactosidase expression (U) in RPS5 strain } \\
\hline GCN4-lacZ & & WT & E144R & $R 225 K$ \\
\hline Optimum context: AAA AÜG AUG & $\begin{array}{l}1 \\
2 \text { sc SUI1 }\end{array}$ & $\begin{array}{l}1.0 \pm 0 \\
1.0 \pm 0\end{array}$ & $\begin{array}{l}20 \pm 4 \\
15 \pm 2\end{array}$ & $\begin{array}{c}4 \pm 1 \\
2 \pm 0.2\end{array}$ \\
\hline Weak context: $\underline{\text { UAA AUG }}$ & $\begin{array}{l}3 \\
4 \\
\text { sc SUI1 }\end{array}$ & $\begin{array}{c}9 \pm 1 \\
18 \pm 5\end{array}$ & $\begin{array}{l}100 \pm 16 \\
120 \pm 17\end{array}$ & $\begin{array}{l}30 \pm 2 \\
50 \pm 3\end{array}$ \\
\hline Poor context: $\underline{\text { UUU }}$ AUG & $\begin{array}{l}5 \\
6 \text { sc SUI1 }\end{array}$ & $\begin{array}{r}40 \pm 5 \\
33 \pm 2\end{array}$ & $\begin{array}{l}170 \pm 30 \\
150 \pm 17\end{array}$ & $\begin{array}{l}70 \pm 10 \\
110 \pm 13\end{array}$ \\
\hline No el. uORF1: AAA AGC I $_{\text {AUG }}$ GCN4-lacZ & 7 & $120 \pm 10$ & $130 \pm 14$ & $120 \pm 11$ \\
\hline
\end{tabular}

Figure 5. RPS5 mutations E144R and R225K confer strong leaky scanning of GCN4 UAUG- 1 in vivo. $\beta$-galactosidase activities were measured in WCEs of strains from Figure $4 C$ harboring the scSUI1 plasmid (as indicated) and el.uORF1 GCN4-lacZ reporters pC3502, pC4466, or pC3503 containing, respectively, the depicted optimum, weak, or poor context of UAUG-1; or UORF-less GCN4-lacZ reporter pC3505 with a mutated UAUG-1. Mean expression values with S.E.M.s were determined from four transformants as described in Figure 3B.

DOI: 10.7554/eLife.07939.009 


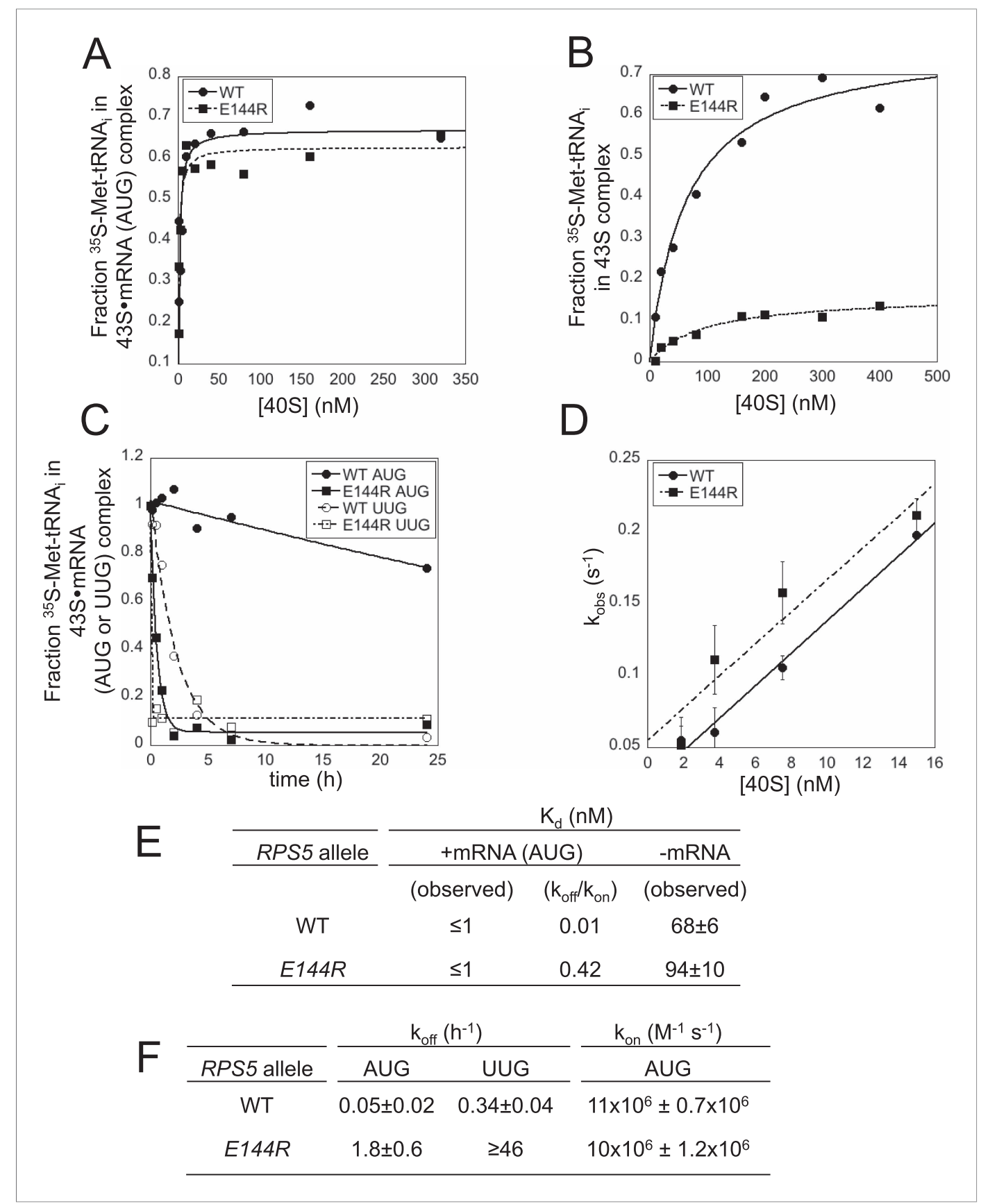

Figure 6. Rps5 Ssu' substitution E144R destabilizes the $P_{I N}$ state in vitro to a greater extent at UUG vs AUG start codons. (A, B) Determination of $K_{d}$ values for TC with $\left.{ }^{35} \mathrm{~S}\right]-M e t-t R N A_{i}$ binding to 40S.elF1.elF1A complexes assembled with WT or E144R mutant 40S subunits and either mRNA (AUG) (A) or without mRNA (B). (C) Analysis of TC dissociation from 43S.mRNA complexes assembled with WT or E144R mutant 40S subunits and either mRNA (AUG) or mRNA(UUG). Representative curves selected from at least three independent experiments are shown. (D) Determination of $k_{\text {on }}$ values for TC binding to 40S.elF1.elF1A complexes from plots of observed rate constants $\left(k_{\text {obs }}\right)$ vs $40 S$ concentration for WT or E144R mutant 40 S subunits and mRNA(AUG). (E, F) $K_{d}$, $k_{\text {off }}$ and $k_{\text {on }}$ values with S.E.M.s determined in (A-D).

DOI: 10.7554/eLife.07939.010

The following figure supplement is available for figure 6:

Figure supplement 1. RPS5 mutation E144R confers a Gcd phenotype, derepressing GCN4-lacZ expression. DOI: 10.7554/eLife.07939.011 
markedly reduced for the E144R complexes (Figure 6B). It was previously proposed that the endpoints of TC binding reactions achieved at saturating $40 \mathrm{~S}$ concentrations reflect the distribution of PICs between open and closed states. The open state was assumed to be unstable during electrophoresis, and thus could not be visualized, leading to endpoints of $<1$ (measured as fractions of TC bound to $40 \mathrm{~S}$ complexes) for reactions using mRNA lacking an AUG codon (Kapp et al., 2006; Kolitz et al., 2009), or tRNA ${ }_{i}{ }^{\text {Met }}$ mutants (Dong et al., 2014), in which the open complex is favored over the closed state. Hence, the reduced endpoint seen in Figure 6B suggests that the closed state of $43 \mathrm{~S}$ complexes formed with E144R mutant ribosomes is unstable and rearranges to the less stable, open conformation during electrophoresis. This interpretation supports the hypothesis that E144R destabilizes the closed state of the PIC.

Direct evidence for this last conclusion came from determining rate constants for TC association and dissociation for $43 \mathrm{~S}$ complexes bound to mRNA. To measure the TC off-rate $\left(\mathrm{k}_{\text {off }}\right), 43 S \cdot \mathrm{mRNA}$ complexes were formed as above using TC assembled with $\left[{ }^{35} \mathrm{~S}\right]-$ Met-tRNA $A_{i}$, and the amount of $\left[{ }^{35} \mathrm{~S}\right]-$ Met-tRNA $\mathrm{A}_{i}$ remaining in the slowly-migrating PIC was measured at different times after adding a chase of excess unlabeled TC. In agreement with previous findings (Kolitz et al., 2009; Dong et al., 2014; Martin-Marcos et al., 2014), TC dissociates very little from WT PICs formed with mRNA(AUG) over the time course of the experiment, yielding a rate constant of only $0.05 \mathrm{hr}^{-1}$ (Figure 6C; summarized in Figure 6F). By contrast, TC dissociation from WT PICs assembled on an otherwise identical mRNA containing a UUG start codon is $\sim$ sevenfold faster $\left(\mathrm{k}_{\text {off }}=0.34 \mathrm{hr}^{-1}\right)$, reflecting the reduced stability of the $P_{I N}$ state at this near-cognate start codon (Figure 6C,F) (Kolitz et al., 2009). Remarkably, for 43S•mRNA(AUG) complexes assembled with E144R 40S subunits, the dissociation rate was increased $\sim 36$-fold compared to that seen for the corresponding WT complexes (from 0.05 $\mathrm{hr}^{-1}$ to $1.8 \mathrm{hr}^{-1}$; Figure $6 C, F$. An even larger increase in $\mathrm{k}_{\text {off }}$ of $\sim 130$-fold was measured for mRNA (UUG) complexes assembled with E144R vs WT $40 \mathrm{~S}$ subunits ( $\geq 46 \mathrm{hr}^{-1}$ vs $0.34 \mathrm{hr}^{-1}$; Figure $6 \mathrm{C}, \mathrm{F}$ ). These findings provide strong biochemical evidence that E144R destabilizes $P_{I N}$ at both AUG and UUG start codons with a relatively stronger effect on the near-cognate triplet, which coincides with the in vivo effects of E144R of reducing recognition of the SUI1 AUG and GCN4 UAUG-1 start codons, and of suppressing UUG initiation on his4-301 mRNA.

The rates of TC association $\left(k_{o n}\right)$ were measured by mixing labeled TC with different concentrations of WT or E144R 40S subunits and saturating elF1, elF1A and mRNA(AUG). Aliquots were removed at different time points, the reactions terminated with excess unlabeled TC, and the amount of labeled TC in PICs was measured by native gel electrophoresis. The slope of the plot of the pseudo-first-order rate constants $\left(k_{o b s}\right)$ for PIC formation vs 40 S concentration yields the second-order rate constant $\left(k_{o n}\right)$ (Kolitz et al., 2009). The $k_{\text {on }}$ values measured for WT and E144R $40 S$ subunits were essentially identical (Figure 6D,F), indicating that PICs formed with the mutant ribosomes assemble the POUT complex and rearrange to $P_{I N}$ at the same rates achieved with WT ribosomes, and that rps-E144R primarily reduces the stability of the $P_{I N}$ state. Calculation of $K_{d}$ values using the measured rate constants $\mathrm{k}_{\text {off }}$ and $\mathrm{k}_{\text {on }}$ reveals that E144R decreases the affinity of TC for 43S•mRNA(AUG) complexes by $\sim 40$-fold (Figure $6 E, \mathrm{k}_{\text {off }} / \mathrm{k}_{\mathrm{on}}$ ). Together, the in vitro experiments demonstrate that $E 144 R$ reduces the affinity of TC for 43S•mRNA PICs by destabilizing the $\mathrm{P}_{\mathrm{IN}}$ state, with a relatively greater effect at UUG vs AUG start codons.

Interestingly, we found that E144R confers the $\mathrm{Gcd}^{-}$phenotype, derepressing a GCN4-lacZ reporter by more than fourfold in non-starvation conditions (Figure 6-figure supplement 1), which indicates a defect in TC binding to $40 \mathrm{~S}$ subunits in vivo. A decreased rate of TC binding derepresses GCN4-lacZ expression because scanning $40 \mathrm{~S}$ subunits that have translated UORF1 and resumed scanning can bypass the start codons of the inhibitory uORFs 2-4 before rebinding TC, and then reinitiate further downstream at the GCN4 AUG codon (Hinnebusch, 2005). Derepression of GCN4lacZ by E144R was evident even in the presence of scSUI1 (Figure 4-figure supplement 2, E144R/scSUI1 vs WT, unstarved), indicating that it does not result solely from the reduced elF1 abundance in this mutant. Because E144R does not reduce the rate of TC binding to 43S.mRNA

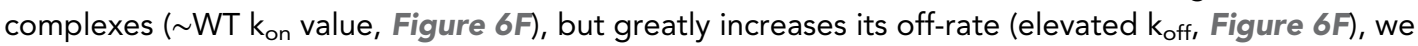
infer that the $\mathrm{Gcd}^{-}$phenotype of E144R arises instead from dissociation of TC from a fraction of re-scanning $40 \mathrm{~S}$ subunits, enabling their bypass of uORFs 2-4, followed by re-binding of TC in time to reinitiate at GCN4. This mechanism was described previously for $\mathrm{Gcd}^{-}$substitutions of $18 \mathrm{~S}$ rRNA residues in the $P$ site of the $40 S$ subunit that, like rps5-E144R, destabilize TC binding in vitro and confer leaky-scanning of an UAUG in vivo (Dong et al., 2008). 


\section{Substitutions in the loop region of the Rps5 $\beta$-hairpin increase fidelity of start codon selection independently of context nucleotides}

Having concluded that rps5-E144R can suppress UUG initiation once native elF1 levels have been restored, we examined the remaining $\beta$-hairpin substitutions we constructed for this $\mathrm{Ssu}^{-}$phenotype. Remarkably, eight different mutations affecting various loop residues were found to suppress the $\mathrm{His}^{+}$ phenotypes conferred by dominant Sui ${ }^{-}$alleles SUI3-2 and SUI5, including R148A/E, R156A/E, R157A/E, A154R and A155E (Figure 7A, -His panel; cf. WT and rps5 strains harboring SUI3-2 or SUI5). With the possible exception of R157E, they also suppressed the dominant Slg- phenotype of SUI5 (Figure 7A, +His panel; cf. WT and rps5 strains harboring SUI5)—a hallmark of known Ssu' mutations in elF1 (Martin-Marcos et alo, 2014). Furthermore, R148A/E, R156A/E and R157A suppressed the elevated UUG:AUG ratio of HIS4-lacZ expression conferred by SUI3-2 (Figure 7B,C), demonstrating bona fide $\mathrm{Ssu}^{-}$phenotypes for these mutations.

In addition to discriminating against non-AUG codons, $\mathrm{Ssu}^{-}$mutations in elF1 and elF1A exacerbate the effect of suboptimal context of the SUI1 AUG start codon and reduce elF1 expression. As such, they exacerbate the differential expression of SUI1-lacZ fusions containing native, suboptimal context vs optimized context by specifically reducing expression of the native-context reporter (Martin-Marcos et al., 2011). However, none of the rps5 Ssu- mutants exhibit diminished elF1 abundance (Figure 7D,E), or selectively diminish expression of the SUI1-lacZ fusion with native context (Figure 7F). Nor do they increase leaky scanning of UAUG-1 regardless of its context in the el. uORF1 reporters (Figure 7-figure supplement 1). Thus, unlike known Ssu- mutations affecting elF1 and elF1A, the rps5 5 su ${ }^{-}$substitutions in the $\beta$-hairpin loop suppress recognition of UUG codons without affecting utilization of AUG codons in poor context.

\section{Ssu $^{-}$substitution R148E destabilizes the $\mathrm{P}_{\mathrm{IN}}$ conformation of the PIC at UUG codons}

To reveal the molecular mechanism of the $\mathrm{Ssu}^{-}$substitutions in the $\beta$-hairpin loop, we analyzed mutant $40 \mathrm{~S}$ subunits purified from rps5-R148E cells in the reconstituted yeast system. Measurements of TC binding to 43S.mRNA(AUG) complexes or 43S complexes without mRNA revealed reaction endpoints (Figure $8 \mathrm{~A}, \mathrm{~B})$ and $\mathrm{K}_{d}$ values $(<1 \mathrm{nM}$ for $43 \mathrm{~S} \cdot \mathrm{mRNA}(\mathrm{AUG})$ complexes, Figure $8 \mathrm{E})$ indistinguishable between WT and R148E mutant ribosomes, as were rates of TC dissociation ( $\left.k_{\text {off }}\right)$ from these complexes containing AUG start codons (Figure 8C, AUG, WT vs R148E; Figure 8F, WT elF2 $\beta$, AUG values). However, R148E increased the $k_{\text {off }}$ for $43 S \cdot m R N A(U U G)$ complexes by $\sim$ twofold, suggesting destabilization of $P_{I N}$ specifically at UUG codons (Figure $8 C, F, W T$ elF2 $\beta$, UUG). To support this conclusion, we repeated the $k_{\text {off }}$ measurements using elF2 harboring the Sui ${ }^{-}$substitution in elF2 $\beta$ encoded by SUI3-2 (S264Y). Consistent with previous results (Martin-Marcos et al., 2014), in reactions with WT 40S subunits, SUI3-2 eliminates detectable TC dissociation from AUG complexes and also delays TC dissociation from UUG complexes (Figure 8D) compared to that seen using WT elF2 (Figure $8 \mathrm{C}$ ), thus decreasing the $\mathrm{k}_{\text {off }}$ for UUG complexes by $\sim$ threefold (Figure 8F; WT elF2 $\beta$ vs elF2 $\beta$-S264Y, WT RPS5, UUG complexes). These results are consistent with the elevated UUG initiation conferred by SUI3-2 in vivo. Importantly, in assays with the SUI3-2 variant of elF2, rps5-R148E produced a marked, fourfold increase in $\mathrm{k}_{\text {off }}$ for the UUG complexes without affecting dissociation of the corresponding AUG complexes (Figure 8D,F). Thus, rps5-R148E preferentially destabilizes the $P_{I N}$ conformation at UUG start codons, overriding the opposing effect of SUI3-2 of enhancing the stability of the UUG complex. These biochemical results are in accordance with our finding that rps5-R148E suppresses the elevated UUG:AUG initiation ratio conferred by SUI3-2 in vivo.

\section{Discussion}

In this study, we obtained genetic and biochemical evidence implicating the $\beta$-hairpin of Rps 5 in achieving efficient and accurate start codon recognition in vivo. In the recent py $48 \mathrm{~S}$ cryo-EM structure (Hussain et alo, 2014), this domain projects into the mRNA exit channel of the 40S subunit and the hairpin loop approaches the key context nucleotide at the -3 position of mRNA. The $\beta$-hairpin also interacts with elF2 $\alpha-\mathrm{DI}$, which mimics an E-site tRNA and contacts the Met-tRNA $A_{i}$ in the P site (Figure 2A). Our genetic findings indicate that the E144R substitution in $\beta$-strand 1 of the hairpin reduces the rate of bulk translation initiation (Figure $3 C$ ) and dramatically impairs recognition of GCN4 uAUG-1 in optimal context by the scanning PIC, conferring a higher incidence of leaky scanning 
A

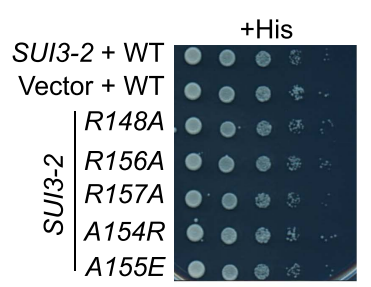

SUI5 + WT 60

Vector + WT $0 \circ *$ *

$R 148 A$ o 0 으

$R 156 A$

$\stackrel{\curvearrowleft}{ら}$

R157A

A155E

SUI3-2 + WT

Vector + WT

$\sim \mid R 148 E$

ले $R 156 E$

की $R 157 E$

SUI5 + WT

Vector + WT

ю $R 148 E$

क $\mid$\begin{tabular}{l|l}
$R 156 E$ \\
$R 157 E$
\end{tabular}

F

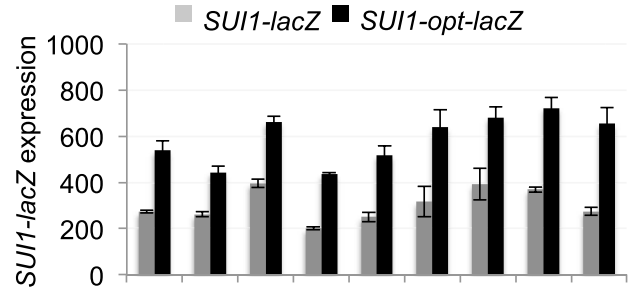

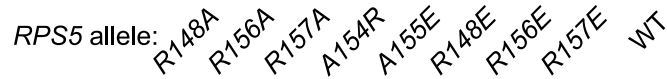
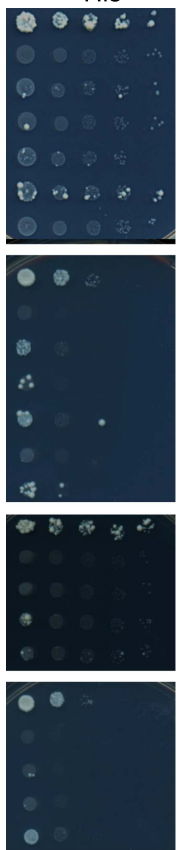

$\mathrm{B}$

E

RPS5

allele:R148A R156A R157A A154R A155E WT

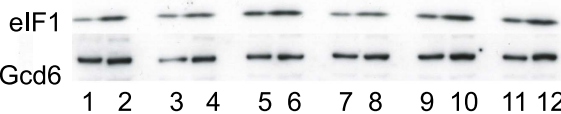

Figure 7. Substitutions in loop residues of the Rps5 $\beta$-hairpin confer Ssu' phenotypes. (A) 10-fold serial dilutions of

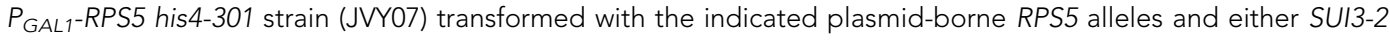
plasmid p4280, SUI5 plasmid p4281, or empty vector were spotted on SD + His + Ura (+His) or SD + Ura (-His) and incubated at $30^{\circ} \mathrm{C}$ for 3 days and 5 days, respectively. (B, C) Strains from (A) also harboring HIS4-lacZ reporters with AUG or UUG start codons (plasmids p367 and p391, respectively) were analyzed as in Figure 3B. Ratios of mean expression of the UUG and AUG reporters calculated from four transformants are plotted with S.E.M.s. Student's t-test indicates that the mean UUG/AUG expression in the RPS5 mutants is significantly reduced when compared to WT $\left({ }^{\star} p<0.05,{ }^{* *} p<0.005\right)$. (D, E) WCEs of his4-301 strains with the indicated RPS5 alleles were subjected to Western analysis as in Figure 4A. (F) WCEs of strains from (D, E) also harboring SUI1-lacZ (pPMB24) or SUI1-opt-lacZ (pPMB25) reporters were assayed for $\beta$-galactosidase activities as described in Figure 4B. Mean expression levels and S.E.M.s from four transformants are plotted.

DOI: 10.7554/eLife.07939.012

The following figure supplement is available for figure 7 :

Figure supplement 1. Substitutions in the loop of the Rps5 $\beta$-hairpin do not increase leaky scanning of GCN4 uAUG-1.

DOI: 10.7554/eLife.07939.013

for the el.uORF1-GCN4-lacZ reporter than described thus far for any initiation factor mutation (Elantak et al., 2010). The E144R mutation also impairs recognition of the SUI1 AUG codon in its native, suboptimal context, and suppresses utilization of the UUG start codon in his4-301 mRNA in different Sui ${ }^{-}$mutants to confer an $\mathrm{Ssu}^{-}$phenotype. Our biochemical analysis of E144R mutant 40S subunits revealed a drastic destabilization of the $P_{I N}$ state of reconstituted 48 S PICs at AUG or UUG 


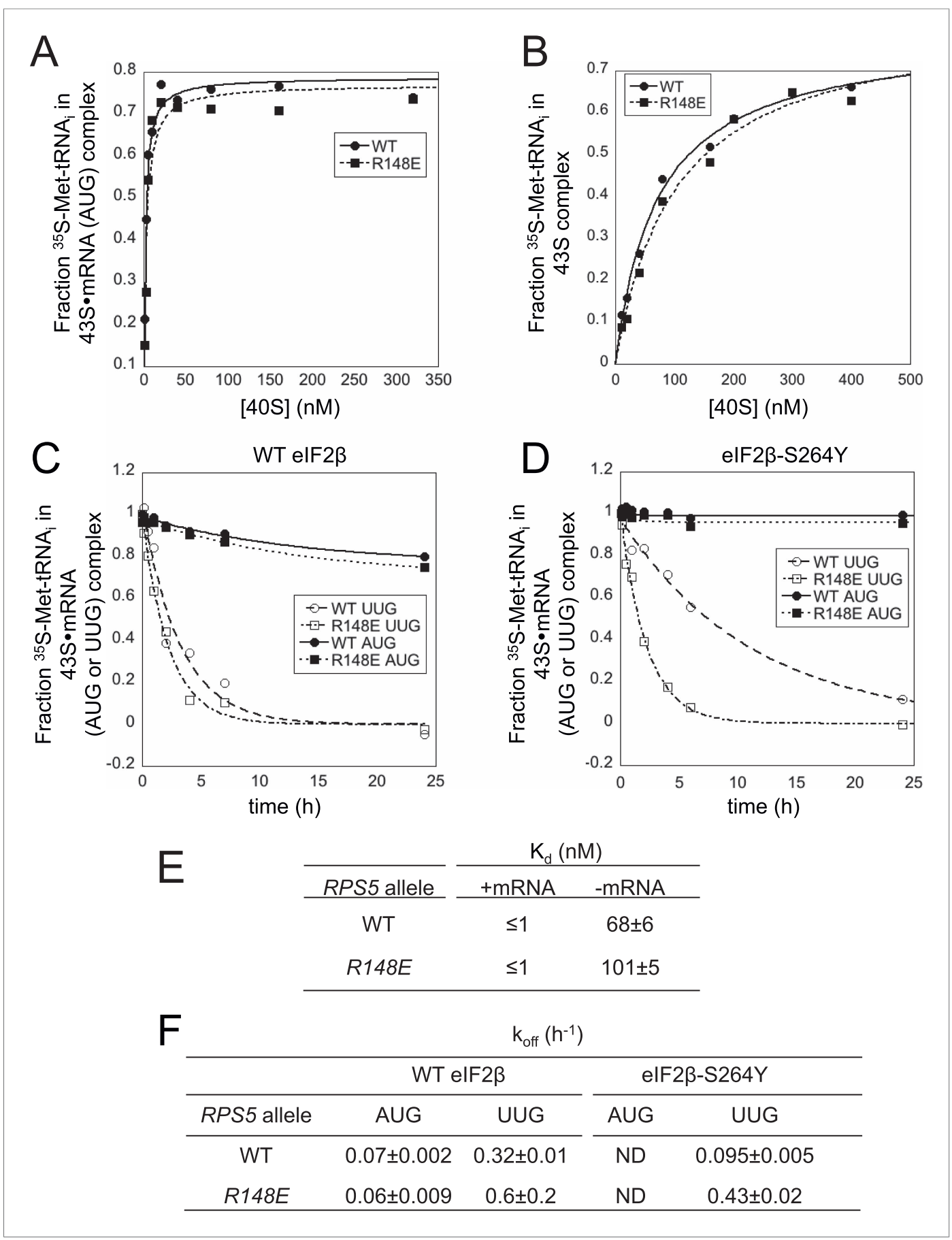

Figure 8. Rps5 Ssu' substitution R148E destabilizes $P_{I N}$ in vitro selectively at UUG codons. (A, B) Determination of $K_{d}$ values for TC with $\left[{ }^{35} \mathrm{~S}\right]-$ Met-tRNA binding to $40 \mathrm{~S} \cdot \mathrm{elF1} \cdot \mathrm{elF1A}$ complexes assembled with WT or R148E mutant 40S subunits and either mRNA (AUG) (A) or without mRNA (B). (C, D) Analysis of TC dissociation from 43S.mRNA complexes assembled with WT or R148E mutant 40S subunits and mRNA(AUG) or mRNA(UUG), conducted using WT elF2 (C) or elF2 $3-S 264 Y$ mutant elF2 (D). Representative curves selected from at least three independent experiments are shown. (E, F) $K_{d}, k_{\text {off }}$ values with S.E.M.s determined in (A-D). ND, no dissociation observed. DOI: 10.7554/eLife.07939.014

codons (Figure 9), with a stronger effect on the inherently less stable UUG complexes. These biochemical phenotypes can account for both the defects in AUG recognition and the reduction in UUG:AUG initiation ratio (Ssu- phenotype) conferred by rps5-E144R in vivo. 


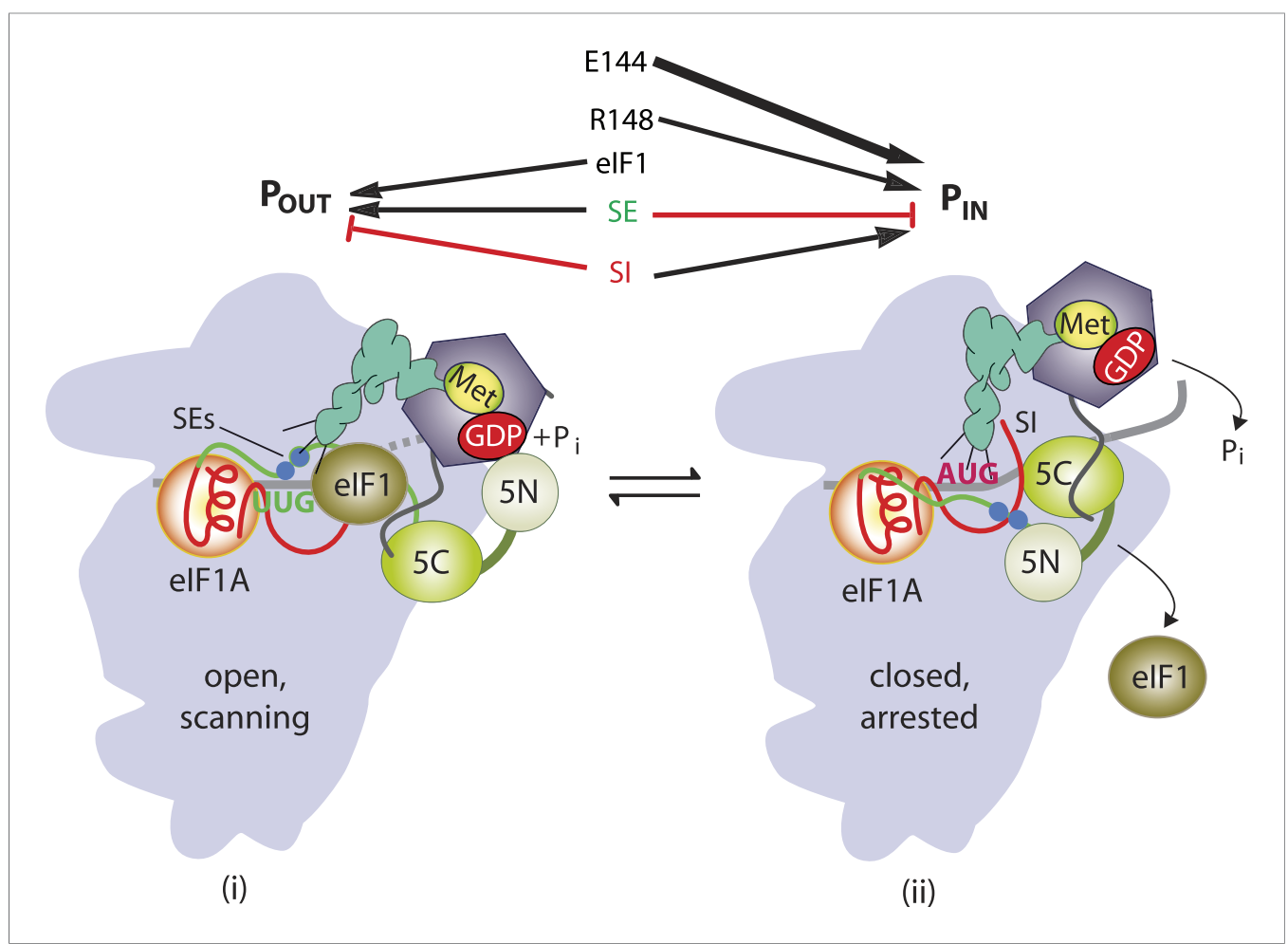

Figure 9. $\beta$-hairpin of Rps 5 has a critical role in start codon recognition during translation initiation by stabilizing initiator tRNA binding to the pre-initiation complex. Model summarizing the role of the conserved $\beta$-hairpin residues in Rps5 in start codon recognition. See Figure 1 for description of the open/Pout and closed/PIN states of the PIC and roles of elF1 and the SE/SI elements of elF1A in regulating conformational rearrangements and reactions accompanying AUG recognition. Results from this study indicate that Rps5 $\beta$-hairpin residues E144 and R148 function in stabilizing the $\mathrm{P}_{\mathbb{I N}}$ conformation of TC binding, with E144 having a stronger effect, as indicated by the thicker arrow.

DOI: 10.7554/eLife.07939.015

The following figure supplement is available for figure 9 :

Figure supplement 1. Rps5 $\beta$-hairpin loop is in proximity to rRNA helix 23. DOI: 10.7554/eLife.07939.016

The E144R mutation conferred a greater increase in leaky scanning of GCN4 UAUG-1 in optimum context ( 20 -fold) vs uAUG-1 in poor context ( fourfold). This difference could be interpreted to indicate that $E 144 R$ disrupts recognition of optimum context nucleotides, so that its deleterious effect on AUG recognition is dampened when the optimum context nucleotides are absent. However, this interpretation would overlook the fact that it is impossible to detect an increase in leaky scanning of uAUG-1 in poor context by 20-fold, as only a $\sim$ threefold reduction in its recognition yields GCN4-lacZ expression essentially indistinguishable from that seen in the absence of uAUG-1 itself (Figure 5, cf. constructs UUUAUG vs AAAAGC in WT cells). Thus, it seems plausible that E144R suppresses uAUG-1 recognition equally well for poor and optimal context. By contrast, E144R and R225K impair recognition of the SUI1 AUG only when it resides in poor context, suggesting that the effects of these Rps5 mutations are limited to the inherently weaker initiation site of native SUI1 mRNA. This conclusion would be consistent with the fact that E144R and $R 225 \mathrm{~K}$ also suppress recognition of the UUG start codon of his4-301 mRNA, which resides in moderately strong context, as near-cognate codons are inherently weaker initiation sites even when present in optimum context.

Extending this last interpretation of $E 144 R$ and $R 225 \mathrm{~K}$-that they preferentially discriminate against poor initiation sites-to explain our findings on leaky scanning of GCN4 uAUG-1 would require a stipulation that $U A U G-1$ is a relatively weak initiation site even with the native optimum context present, which seems at odds with the fact that nearly all scanning ribosomes recognize native uAUG-1 in WT GCN4 mRNA (Grant et al., 1994). However, one distinctive feature of WT uORF1 and 
the elongated el.uORF1 contained in our leaky scanning reporter is the absence of typical coding sequences $3^{\prime}$ of the UAUG-1 start codon. WT uORF1 is only 3 codons long, and much of el.uORF1 is derived from non-translated triplets that normally reside between uORF4 and the GCN4 coding sequence. This region has a relatively low propensity for secondary structure (Kertesz et al., 2010), which might enable elongating ribosomes to clear the initiation region more rapidly than occurs with more typical coding sequences. In fact, the properties of the leaky scanning reporter insure that the increases in GCN4-lacZ expression observed in the Rps5 mutants reflect diminished recognition of uAUG-1 relative to the main ORF start codon by scanning PICs. Considering that the rps 5 mutations appear to have no effect on recognition of the main ORF AUG in the GCN4-lacZ construct lacking el. uORF1 (Figure 5, row 7), the presence of greater secondary structure in the main ORF could reduce the rate of scanning through the initiation region to promote start codon recognition in a way that would be lacking at the el.uORF1 start codon. If elongating ribosomes located in the initiation region can enhance initiation by this mechanism, this could compensate for the reduction in $\mathrm{P}_{\mathrm{IN}}$ stability conferred by E144R and R225K for the SUI1 and GCN4 initiation regions in a way that would not occur for el.uORF1, making the latter sensitive to the destabilizing effects of these mutations even with optimum context present. Consistent with this scenario, it was shown recently that the presence of slowly-translated codons near the AUG codon can affect the initiation rate in yeast cells (Chu et al., 2014). Thus, it seems plausible that $E 144 R$ and $R 225 K$ decrease the efficiency of start codon recognition only for weak initiation sites, including near-cognate UUG codons and sub-optimal AUG start sites, without reducing recognition of AUG codons in strong context that initiate structured coding sequences.

The impaired recognition of the native SUI1 AUG codon and attendant reduced synthesis of elF1 conferred by the rps5-E144R and -R225K mutations evokes increased recognition of near-cognate, UUG start codons. While this elevated UUG:AUG initiation ratio is the expected outcome of diminished elF1 abundance (Ivanov et al., 2010; Martin-Marcos et al., 2011), previously described $\mathrm{Ssu}^{-}$substitutions in elF1 and elF1A reduce elF1 levels by the same mechanism described here-discriminating against the weak context of the native SUI1 AUG-but they suppress, rather than elevate, the UUG:AUG initiation ratio despite reduced elF1 levels (Martin-Marcos et al., 2011). Thus, these elF1 and elF1A Ssu ${ }^{-}$substitutions appear to have a stronger effect than rps5-E144R and $-R 225 \mathrm{~K}$ in blocking selection of UUG start codons. On the other hand, the elF1A and elF1 Ssu substitutions confer much smaller increases in leaky scanning of GCN4 uAUG-1 (Fekete et al., 2007) (Pilar Martin Marcos and AGH, unpublished observations) compared to that seen here for rps5$E 144 R$, thus indicating a relatively greater defect in AUG recognition for the Rps5 mutation.

In addition to the mutations affecting the upper, structured portion of the $\beta$-hairpin loop (E144R and $\mathrm{R} 225 \mathrm{~K}$ ), we also identified $\mathrm{Ssu}^{-}$substitutions in the loop region that discriminate against UUG codons in the presence of Sui ${ }^{-}$substitutions in elF5 or elF2 $\beta$. Consistent with this, an exemplar of such mutations, rps5-R148E, specifically destabilized the $P_{I N}$ state formed at UUG, but not AUG, start codons in reconstituted PICs in vitro. The Rps5 loop substitutions do not discriminate against the weak context of the SUI1 AUG codon, nor increase leaky scanning of el.uORF1 even when uAUG-1 resides in poor context, and thus exclusively destabilize PICs lacking a cognate (AUG) start codon. They differ from previously described Ssu' substitutions in elF1 (Martin-Marcos et al., 2011) in that the Rps5 substitutions efficiently suppress UUG initiation but do not discriminate against the poor context of the native SUI1 AUG codon. This distinction might be explained by noting that elF1 is the principal 'gate-keeper' that blocks utilization of weak initiation sites (Hinnebusch, 2014). As the elF1 $\mathrm{Ssu}^{-}$substitutions delay elF1 release from the 40S subunit on start codon recognition (Martin-Marcos et al., 2013), they might discriminate more broadly against unstable PICs regardless of whether they lack strong context or a perfect codon:anticodon duplex in the P site. Our Rps5 loop substitutions, by contrast, appear to have a more nuanced effect that destabilizes $P_{I N}$ only when a mismatch occurs in the codon:anticodon duplex itself. As summarized in Figure 9, our results indicate that both E144 and R148 promote start codon selection by stabilizing the $P_{I N}$ state, and the finding that E144R reduces initiation at both UUG and sub-optimal AUG codons, while R148E impairs only UUG recognition, can be explained as the result of a relatively stronger contribution of E144 vs R148 to the stability of the $P_{I N}$ state.

There are several possibilities to explain how perturbing the Rps5 $\beta$-hairpin destabilizes the $P_{I N}$ state and reduces start codon recognition. The proximity of the hairpin loop to the E site (Figure 2) suggests a disruption of Rps5 contacts with the context nucleotides in mRNA. Indeed, R156 in the 
loop interacts with the backbone of rRNA helix 23 , which in turn contacts the -3 context nucleotide (Figure 9-figure supplement 1) (Hussain et al., 2014). If this interaction promotes the $P_{\text {IN }}$ state, it would help explain why loop residue substitutions impair recognition of UUG start codons $\left(\mathrm{Ssu}^{-}\right.$ phenotype). However, except for the lethal substitution G151S, all of the substitutions affecting loop residues we examined-G151 through Q158-have weaker phenotypes compared to the E144R substitution in $\beta$-strand 1 of the hairpin itself, distant from the context nucleotides. Thus, perhaps structural alteration of the $\beta$-hairpin by E144R indirectly perturbs the conformation of the $\mathrm{N}$-terminal tail of yeast Rps5, which promotes AUG recognition by its interaction with Rps16/uS9 (Ghosh et al., 2014), whose C-terminal tail closely approaches the codon-anticodon duplex in the P site (Hussain et al., 2014). Alternatively, E144R might affect the conformation or location of ribosomal proteins Rps28 and Rps14, also located in the exit channel and in contact with the Rps5 $\beta$-hairpin (Hussain et al., 2014), or of domain 1 of elF2 $\alpha$, which interacts with other regions of Rps 5 as well as Met-tRNA in the $P_{I N}$ complex (Figure 2). In these latter scenarios, the inherent flexibility of the Rps 5 hairpin loop could prevent loop substitutions from altering the orientation of the $\beta$-hairpin and attendant perturbations within the PIC compared to effects exerted by $E 144 R$ or $R 225 K$ on the structured portion of the hairpin.

The $\beta$-hairpin of uS7 also protrudes into the mRNA exit channel of bacterial ribosomes in position to interact with mRNA residues just upstream from the P site codon (Jenner et al., 2007). In bacterial elongation complexes, the hairpin is also in proximity to E-site tRNA, and truncation of the hairpin increases the frequency of frameshifting, most likely by allowing premature dissociation of the E-site tRNA (Devaraj et al., 2009). Interestingly, in the yeast py48S PIC, elF2 $\alpha$-D1 essentially occupies the position of E-site tRNA (Hussain et al., 2014), in accordance with our suggestion that altering the $\beta$-hairpin of yeast uS7/Rps 5 could impair start codon selection by perturbing the position or flexibility of elF2 $\alpha$-D1. Regardless of the exact mechanisms involved, the strong impairment of AUG recognition in vivo and marked destabilization of the $P_{I N}$ state in vitro conferred by E144R dramatically illustrates that a $40 \mathrm{~S}$ ribosomal protein functions as an equal partner with soluble initiation factors in ensuring efficient and accurate start codon recognition.

\section{Materials and methods}

\section{Plasmids and yeast strains}

Yeast strains and plasmids are listed in Supplementary files 2, 3, respectively.

Yeast strains used in this study are listed in Supplementary file 2. The $P_{\text {GAL1-RPS5 strain JVY07 was }}$ generated from HLV01a (MATa ura3-52 trp14-63 leu2-3112 his4-301(ACG)) by the one-step PCR strategy (Longtine et al., 1998) using the kanMX4 cassette and selecting for resistance to kanamycin on rich medium containing galactose as carbon source (YPGal). Integration of the kanMX:PGAL1 promoter cassette at RPS5 was verified by PCR analysis of genomic DNA using the appropriate primers. JVY07 was shown to be inviable on glucose medium (where the GAL1 promoter is repressed) in a manner fully complemented by plasmid-borne RPS5 alleles on pJV01 and pJV09. Derivatives of JVY07 harboring low copy LEU2 plasmids containing WT (pJV09) or mutant RPS5 alleles (pJV12pJV53), listed in Supplementary file 3, were generated by transformation.

To avoid possible contamination with WT $40 \mathrm{~S}$ subunits (from leaky expression of $P_{\text {GAL1-RPS5 on }}$ glucose medium) transformants of JVY07 containing rps5 alleles were not used for purifying mutant $40 \mathrm{~S}$ subunits, and haploid strains harboring the relevant rps 5 alleles as the only source of Rps 5 were generated for this purpose. Diploid strain F2009/YSC1021-672858 (MATa/MAT $\alpha$ ura3- $\Delta 0 /$ ura3- $\Delta 0$ leu2- $\Delta 0 /$ leu2- $\Delta 0$ his3 $\Delta-1 /$ his3 $\Delta-1$ lys2- $\Delta 0 /$ LYS2 met15- $\Delta 0 / M E T 15$ rps5 $\Delta:: k a n M X / R P S 5)$ was transformed with URA3 RPS5 plasmid pJV38 and sporulated. Tetrads were dissected and analyzed for resistance to $\mathrm{G} 418$ to identify rps54::kanMX ascospores, which was verified by PCR analysis of genomic DNA with appropriate primers. One such strain was selected as JVY11, and used as host to replace pJV38 with plasmids pJV09, pJV13 and pJV39, harboring RPS5, rps5-E144R, rps5-R148E, respectively, by plasmid-shuffling on medium containing 5-FOA (Boeke et al., 1987), resulting in strains JVY29, JVY15 and JVY52.

Plasmids used in this study are listed in Supplementary file 3. pJV01 was made by inserting into pRS315 a $1.6 \mathrm{~kb}$ BamHI restriction fragment containing RPS5 flanked by 640 bp upstream and $320 \mathrm{bp}$ downstream of the coding sequences that was amplified from genomic DNA of strain HLV01a. A Bglll restriction site was introduced into pJV01 $120 \mathrm{bp}$ upstream of the RPS5 ORF using the QuikChange 
site-directed mutagenesis system (Agilent Technologies, Santa Clara, CA) to create pJV09, which was verified by DNA sequencing of the entire $1.6 \mathrm{~kb}$ insert. Introduction of the Bglll site did not appreciably affect RPS5 expression, as pJV09 and pJV01 were indistinguishable for complementation of strain JVY07 for growth on glucose medium. The insert from pJV09 was sub-cloned into pRS316 to create pJV38. RPS5 fragments were amplified by fusion PCR to introduce the desired site-directed mutations, using primers listed in Supplementary file 4 and pJV09 as template DNA. The mutagenized fragments were digested with $\mathrm{Bglll}$ and $\mathrm{Ndel}$ and inserted between the same two restriction sites in pJV09, to produce pJV12-pJV52 (Supplementary file 3). Plasmid pJV53 was constructed similarly by using primers R225K, R225K_r and pJV13 (that was verified by sequencing) as template DNA. All constructs were verified by DNA sequencing of $1 \mathrm{~kb}$ from the inserted Bglll site beyond the Ndel restriction site, covering the entire RPS5 ORF.

\section{Biochemical analyses of yeast cells}

Assays of $\beta$-galactosidase activity in whole-cell extracts (WCEs) were performed as described previously (Moehle and Hinnebusch, 1991). The sequence context of the start codon for both AUG and UUG HIS4-lacZ reporters is: 5'-AUA(AUG/UUG)G-3'. For Western analysis, WCEs were prepared by trichloroacetic acid extraction as described (Reid and Schatz, 1982), and immunoblot analysis was conducted as described previously (Martin-Marcos et al., 2011) with antibodies against elF1 (Valasek et al., 2004) and Gcd6 (Bushman et al., 1993). Enhanced chemiluminescence (Amersham) was used to visualize immune complexes, and signal intensities were quantified by densitometry using NIH ImageJ software.

\section{Polysome profile analysis}

For polysome analysis, strains were grown in SD + His + Ura $+\operatorname{Trp}$ at $30^{\circ} \mathrm{C}$ to $\mathrm{A}_{600}, \sim 1$. Cycloheximide was added $(50 \mu \mathrm{g} / \mathrm{ml}) 5 \mathrm{~min}$ prior to harvesting, and WCE was prepared in breaking buffer (20 mM Tris- $\mathrm{HCl}, \mathrm{pH} 7.5,50 \mathrm{mM} \mathrm{KCl}, 10 \mathrm{mM} \mathrm{MgCl}$, $1 \mathrm{mM}$ dithiothreitol, $5 \mathrm{mM} \mathrm{NaF}, 1 \mathrm{mM}$ phenylmethylsulfonyl fluoride, 1 Complete EDTA-free Protease Inhibitor Tablet (Roche)/50 ml buffer). $15 \mathrm{~A}_{260}$ units of WCE was separated by velocity sedimentation on a $4.5-45 \%$ sucrose gradient by centrifugation at $39,000 \mathrm{rpm}$ for $3 \mathrm{hr}$ in an SW41Ti rotor (Beckman). Gradient fractions were scanned at $254 \mathrm{~nm}$ to visualize ribosomal species.

\section{Biochemical analysis in the reconstituted yeast translation system}

Initiation factors elF1A and elF1 were expressed in Escherichia coli and purified using the IMPACT system (NEB), and His 6 -tagged elF2 was overexpressed in yeast and purified as described (Acker et al., 2007). WT and mutant 40S subunits were purified from yeast as described previously (Acker et al., 2007). Model mRNAs with the sequences 5 '-GGAA[UC $]_{7} U A U G[C U]_{10} C-3^{\prime}$ and $5^{\prime}-G G A A[U C]_{7} U U U G$ $[\mathrm{CU}]_{10} \mathrm{C}-3^{\prime}$ were purchased from Thermo Scientific. Yeast $t R N A_{i}{ }^{M e t}$ was synthesized from a hammerhead fusion template using T7 RNA polymerase and charged with $\left.{ }^{35} \mathrm{~S}\right]$-methionine or unlabeled methionine as previously described (Acker et alo, 2007). $K_{d}$ values of TC (assembled with [ ${ }^{35}$ S]-Met-tRNA $A_{i}$ ) and 40S•elF1・elF1A•mRNA PICs, and rate constants of TC association/dissociation for the same PICs, were determined by gel shift assays as described previously (Kolitz et al., 2009) with the minor modifications described below.

\section{Buffers and reagents}

For all experiments, the reaction buffer was $30 \mathrm{mM}$ Hepes- $\mathrm{KOH}(\mathrm{pH} 7.4), 100 \mathrm{mM}$ potassium acetate (pH 7.4), $3 \mathrm{mM}$ magnesium acetate, and $2 \mathrm{mM}$ dithiothreitol. The composition of the enzyme buffer was $20 \mathrm{mM}$ Hepes-KOH (pH 7.4), $100 \mathrm{mM} \mathrm{KOAc} \mathrm{(pH} \mathrm{7.4),} 2 \mathrm{mM} \mathrm{DTT}$, and 10\% glycerol.

Measurements of TC $K_{d}$ values in 40S.elF1.elF1A and 40S·elF1.elF1A.mRNA complexes

Gel shift assays were performed as described previously (Kolitz et al., 2009) with the following modifications. GDPNP. $\mathrm{Mg}^{2+}$ was used at $100 \mu \mathrm{M}$, as this lower concentration was found not to reduce complex formation. TC was pre-formed for $15 \mathrm{~min}$ at $26^{\circ} \mathrm{C}$ before mixing with $40 \mathrm{~S}$ subunits at various concentrations and the remaining factors. 10-fold concentrated stocks of 405 subunits were prepared by serial dilution. Final component concentrations in the reactions were: $1 \mathrm{nM}\left[{ }^{35} \mathrm{~S}\right]-\mathrm{Met}_{-\mathrm{RNA}}, 100 \mu \mathrm{M}$ GDPNP, $200 \mathrm{nM}$ elF2, $1 \mu \mathrm{M}$ each of elF1 and elF1A, and mRNA (when present) at $1 \mu \mathrm{M}$. Complexes 
containing mRNA(AUG) were incubated at least $30 \mathrm{~min}$ at $26^{\circ} \mathrm{C}$, whereas complexes lacking mRNA were incubated at least $45 \mathrm{~min}$ at $26^{\circ} \mathrm{C}$. Total reaction volumes were $12 \mu \mathrm{l}$ and were mixed with $3 \mu \mathrm{l}$ of native gel dye (Acker et al., 2007) before resolving $13 \mu \mathrm{l}$ by gel electrophoresis at $25 \mathrm{~W}$ for $30-45 \mathrm{~min}$. Following electrophoresis, gel wells were washed to remove excess free $\left[{ }^{35} \mathrm{~S}\right]-\mathrm{Met}-\mathrm{tRNA} \mathrm{A}_{\mathrm{i}}$. The fraction of [ $\left.{ }^{35} \mathrm{~S}\right]-$ Met-tRNA $i$ bound to $40 \mathrm{~S} \cdot \mathrm{elF1} \cdot \mathrm{elF1A}$ or $40 \mathrm{~S} \cdot \mathrm{elF1} \cdot \mathrm{elF1A} \cdot \mathrm{mRNA}$ complexes was measured using a Phosphorlmager, plotted against the $40 \mathrm{~S}$ subunit concentration, and the data were fit with a hyperbolic or quadratic binding equation, with the latter employed for tight binding.

\section{Kinetics of TC association and dissociation in 40S.elF1.elF1A.mRNA complexes}

Measurements were carried out essentially as described previously (Kolitz et al., 2009). Reactions were performed in Recon buffer at final component concentrations of $250 \mathrm{nM}$ elF2, $1 \mathrm{nM}$ [ $\left.{ }^{35} \mathrm{~S}\right]-$ MettRNA $_{i}, 1 \mu \mathrm{M}$ elF1, $1 \mu \mathrm{M}$ elF1A, and $10 \mu \mathrm{M}$ mRNA. Dissociation rates ( $\mathrm{k}_{\text {off }}$ values) were measured by monitoring the amount of labeled TC bound in 40S.elF1.elF1A.mRNA complexes over time using a native gel shift assay, as described above. 40S.elF1.elF1A.mRNA complexes were preassembled for $2 \mathrm{hr}$ at $26^{\circ} \mathrm{C}$ in a reaction vol of $60 \mu \mathrm{l}$. Aliquots of $6 \mu \mathrm{l}$ were removed at different times and mixed with $3 \mu \mathrm{l}$ of a chase of unlabeled WT TC, containing $750 \mathrm{nM}$ elF2 and $300 \mathrm{nM}$ Met-tRNA $\mathrm{A}_{\mathrm{i}}$, representing a 300-fold excess over labeled TC. After addition of the chase to all time points, the reactions were mixed with native gel dye and loaded directly on a running native gel. A converging time course was employed so that all samples could be loaded simultaneously. The fraction of [ $\left.{ }^{35} \mathrm{~S}\right]-\mathrm{Met}-\mathrm{tRNA} \mathrm{A}_{i}$ in $43 \mathrm{~S}$ complexes was determined as described above and the data were fit with a single exponential equation. Association rates were measured by mixing labeled TC with 40S·elF1·elF1A.mRNA complexes and quenching the binding reaction at various times by adding a 300-fold excess of unlabeled WT TC. Reactions were assembled as described above using $6 \mu$ of sample and $3 \mu$ of chase, and completed reactions were mixed with $2 \mu \mathrm{l}$ of native gel dye before resolving $10 \mu \mathrm{l}$ by gel electrophoresis. As above, samples were loaded within min on a running native gel. The $k_{\text {obs }}$ values were calculated by plotting the fraction of $\left[{ }^{35} \mathrm{~S}\right]-$ Met-tRNA bound to $40 \mathrm{~S} \cdot \mathrm{elF1} \cdot \mathrm{elF1A} \cdot \mathrm{mRNA}$ complexes against time and fitting the data with a single exponential equation. The resulting $k_{\text {obs }}$ values were plotted vs the $40 S$ subunit concentrations used in different experiments and the data were fit to a straight line. The slopes of these lines correspond to the second-order rate constants $\left(k_{o n}\right)$ for TC binding.

\section{Acknowledgements}

We thank Jagpreet Nanda for guidance with the in vitro reconstitution assays, and Jon Lorsch and members of our laboratories for helpful advice. This work was supported in part by the Intramural Program of the National Institutes of Health.

\section{Additional information}

Funding

\begin{tabular}{lll} 
Funder & Grant reference & Author \\
\hline National Institutes of Health (NIH) & Intramural Program & Alan G Hinnebusch \\
\hline
\end{tabular}

The funder had no role in study design, data collection and interpretation, or the decision to submit the work for publication.

Author contributions

JV, Conception and design, Acquisition of data, Analysis and interpretation of data, Drafting or revising the article; YP, Conception and design, Acquisition of data; TED, AGH, Conception and design, Analysis and interpretation of data, Drafting or revising the article

\section{Additional files}

Supplementary files

- Supplementary file 1. Phenotypes of RPS5 mutants.

DOI: $10.7554 /$ LLife.07939.017 
- Supplementary file 2. Yeast strains employed in this study.

DOI: 10.7554/eLife.07939.018

- Supplementary file 3. Plasmids employed in this study.

DOI: 10.7554/eLife.07939.019

- Supplementary file 4. Oligonucleotide primers employed for mutagenesis in this study.

DOI: $10.7554 /$ LLife.07939.020

\section{References}

Acker MG, Kolitz SE, Mitchell SF, Nanda JS, Lorsch JR. 2007. Reconstitution of yeast translation initiation. Methods in Enzymology 430:111-145. doi: 10.1016/S0076-6879(07)30006-2.

Algire MA, Maag D, Lorsch JR. 2005. Pi release from elF2, not GTP hydrolysis, is the step controlled by start-site selection during eukaryotic translation initiation. Molecular Cell 20:251-262. doi: 10.1016/j.molcel.2005.09.008.

Alone PV, Cao C, Dever TE. 2008. Translation initiation factor 2gamma mutant alters start codon selection independent of Met-tRNA binding. Molecular and Cellular Biology 28:6877-6888. doi: 10.1128/MCB.01147-08.

Ben-Shem A, Garreau de Loubresse N, Melnikov S, Jenner L, Yusupova G, Yusupov M. 2011. The structure of the eukaryotic ribosome at 3.0 A Resolution. Science 334:1524-1529. doi: 10.1126/science.1212642.

Boeke JD, Trueheart J, Natsoulis G, Fink GR. 1987. 5-fluoroorotic acid as a selective agent in yeast molecular genetics. Methods in Enzymology 154:164-175. doi: 10.1016/0076-6879(87)54076-9.

Bushman JL, Asuru AI, Matts RL, Hinnebusch AG. 1993. Evidence that GCD6 and GCD7, translational regulators of GCN4 are subunits of the guanine nucleotide exchange factor for elF-2 in Saccharomyces cerevisiae. Molecular and Cellular Biology 13:1920-1932.

Cheung YN, Maag D, Mitchell SF, Fekete CA, Algire MA, Takacs JE, Shirokikh N, Pestova T, Lorsch JR, Hinnebusch AG. 2007. Dissociation of elF1 from the $40 \mathrm{~S}$ ribosomal subunit is a key step in start codon selection in vivo. Genes \& Development 21:1217-1230. doi: 10.1101/gad.1528307.

Chu D, Kazana E, Bellanger N, Singh T, Tuite MF, von der Haar T. 2014. Translation elongation can control translation initiation on eukaryotic mRNAs. The EMBO Journal 33:21-34. doi: 10.1002/embj.201385651.

Devaraj A, Shoji S, Holbrook ED, Fredrick K. 2009. A role for the 30 S subunit E site in maintenance of the translational reading frame. RNA 15:255-265. doi: 10.1261/rna.1320109.

Dong J, Munoz A, Kolitz SE, Saini AK, Chiu WL, Rahman H, Lorsch JR, Hinnebusch AG. 2014. Conserved residues in yeast initiator tRNA calibrate initiation accuracy by regulating preinitiation complex stability at the start codon. Genes \& Development 28:502-520. doi: 10.1101/gad.236547.113.

Dong J, Nanda JS, Rahman H, Pruitt MR, Shin BS, Wong CM, Lorsch JR, Hinnebusch AG. 2008. Genetic identification of yeast $18 \mathrm{~S}$ rRNA residues required for efficient recruitment of initiator tRNA(Met) and AUG selection. Genes \& Development 22:2242-2255. doi: 10.1101/gad.1696608.

Dorris DR, Erickson FL, Hannig EM. 1995. Mutations in GCD11, the structural gene for elF-2 $\gamma$ in yeast, alter translational regulation of GCN4 and the selection of the start site for protein synthesis. The EMBO Journal 14:2239-2249.

Elantak L, Wagner S, Herrmannova A, Karaskova M, Rutkai E, Lukavsky P, Valasek L. 2010. The indispensable $\mathrm{N}$-terminal half of elF3j/HCR1 cooperates with its structurally conserved binding partner elF3b/PRT1-RRM and with elF1A in stringent AUG selection. Journal of Molecular Biology 396:1097-1116. doi: 10.1016/j.jmb.2009.12.047.

Fekete CA, Mitchell SF, Cherkasova VA, Applefield D, Algire MA, Maag D, Saini A, Lorsch JR, Hinnebusch AG. 2007. $\mathrm{N}$-and $\mathrm{C}$-terminal residues of elF1A have opposing effects on the fidelity of start codon selection. The EMBO Journal 26:1602-1614. doi: 10.1038/sj.emboj.7601613.

Ghosh A, Jindal S, Bentley AA, Hinnebusch AG, Komar AA. 2014. Rps5-Rps16 communication is essential for efficient translation initiation in yeast S. cerevisiae. Nucleic Acids Research 42:8537-8555. doi: 10.1093/nar/gku550.

Grant CM, Miller PF, Hinnebusch AG. 1994. Requirements for intercistronic distance and level of elF-2 activity in reinitiation on GCN4 mRNA varies with the downstream cistron. Molecular and Cellular Biology 14:2616-2628. doi: 10.1128/MCB.14.4.2616.

Hashem Y, des Georges A, Dhote V, Langlois R, Liao HY, Grassucci RA, Hellen CU, Pestova TV, Frank J. 2013. Structure of the mammalian ribosomal 43S preinitiation complex bound to the scanning factor DHX29. Cell 153: 1108-1119. doi: 10.1016/j.cell.2013.04.036.

Hinnebusch AG. 2005. Translational regulation of GCN4 and the general amino acid control of yeast. Annual Review of Microbiology 59:407-450. doi: 10.1146/annurev.micro.59.031805.133833.

Hinnebusch AG. 2011. Molecular mechanism of scanning and start codon selection in eukaryotes. Microbiology and Molecular Biology Reviews 75:434-467. doi: 10.1128/MMBR.00008-11.

Hinnebusch AG, Lorsch JR. 2012. The mechanism of eukaryotic translation initiation: new insights and challenges. Cold Spring Harbor Perspectives in Biology 4:a011544. doi: 10.1101/cshperspect.a011544.

Hinnebusch AG. 2014. The scanning mechanism of eukaryotic translation initiation. Annual Review of Biochemistry 83:779-812. doi: 10.1146/annurev-biochem-060713-035802.

Huang H, Yoon H, Hannig EM, Donahue TF. 1997. GTP hydrolysis controls stringent selection of the AUG start codon during translation initiation in Saccharomyces cerevisiae. Genes \& Development 11:2396-2413. doi: 10. 1101/gad.11.18.2396.

Hussain T, Llacer JL, Fernandez IS, Munoz A, Martin-Marcos P, Savva CG, Lorsch JR, Hinnebusch AG, Ramakrishnan V. 2014. Structural changes enable start codon recognition by the eukaryotic translation initiation complex. Cell 159:597-607. doi: 10.1016/j.cell.2014.10.001. 
Ivanov IP, Loughran G, Sachs MS, Atkins JF. 2010. Initiation context modulates autoregulation of eukaryotic translation initiation factor 1 (elF1). Proceedings of the National Academy of Sciences of USA 107:18056-18060. doi: 10.1073/pnas.1009269107.

Jenner L, Rees B, Yusupov M, Yusupova G. 2007. Messenger RNA conformations in the ribosomal E site revealed by X-ray crystallography. EMBO Reports 8:846-850. doi: 10.1038/sj.embor.7401044.

Kapp LD, Kolitz SE, Lorsch JR. 2006. Yeast initiator tRNA identity elements cooperate to influence multiple steps of translation initiation. RNA 12:751-764. doi: 10.1261/rna.2263906.

Kertesz M, Wan Y, Mazor E, Rinn JL, Nutter RC, Chang HY, Segal E. 2010. Genome-wide measurement of RNA secondary structure in yeast. Nature 467:103-107. doi: 10.1038/nature09322.

Kolitz SE, Takacs JE, Lorsch JR. 2009. Kinetic and thermodynamic analysis of the role of start codon/anticodon base pairing during eukaryotic translation initiation. RNA 15:138-152. doi: 10.1261/rna.1318509.

Lomakin IB, Steitz TA. 2013. The initiation of mammalian protein synthesis and mRNA scanning mechanism. Nature 500:307-311. doi: 10.1038/nature12355.

Longtine MS, McKenzie A III, Demarini DJ, Shah NG, Wach A, Brachat A, Philippsen P, Pringle JR. 1998. Additonal modules for versatile and economical PCR-based gene deletion and modification in Saccharomyces cerevisiae. Yeast 14:953-961. doi: 10.1002/(SICI)1097-0061(199807)14:10<953::AID-YEA293>3.0.CO;2-U.

Maag D, Fekete CA, Gryczynski Z, Lorsch JR. 2005. A conformational change in the eukaryotic translation preinitiation complex and release of elF1 signal recognition of the start codon. Molecular Cell 17:265-275. doi: 10.1016/j.molcel.2004.11.051.

Martin-Marcos P, Cheung YN, Hinnebusch AG. 2011. Functional elements in initiation factors 1, 1A, and 2beta discriminate against poor AUG context and non-AUG start codons. Molecular and Cellular Biology 31: 4814-4831. doi: 10.1128/MCB.05819-11.

Martin-Marcos P, Nanda J, Luna RE, Wagner G, Lorsch JR, Hinnebusch AG. 2013. beta-hairpin loop of elF1 mediates $40 \mathrm{~S}$ ribosome binding to regulate initiator tRNAMet recruitment and accuracy of AUG selection in vivo. The Journal of Biological Chemistry 288:27546-27562. doi: 10.1074/jbc.M113.498642.

Martin-Marcos P, Nanda JS, Luna RE, Zhang F, Saini AK, Cherkasova VA, Wagner G, Lorsch JR, Hinnebusch AG. 2014. Enhanced elF1 binding to the $40 \mathrm{~S}$ ribosome impedes conformational rearrangements of the preinitiation complex and elevates initiation accuracy. RNA 20:150-167. doi: 10.1261/rna.042069.113.

Moehle CM, Hinnebusch AG. 1991. Association of RAP1 binding sites with stringent control of ribosomal protein gene transcription in Saccharomyces cerevisiae. Molecular and Cellular Biology 11:2723-2735.

Nanda JS, Cheung YN, Takacs JE, Martin-Marcos P, Saini AK, Hinnebusch AG, Lorsch JR. 2009. elF1 controls multiple steps in start codon recognition during eukaryotic translation initiation. Journal of Molecular Biology 394:268-285. doi: 10.1016/j.jmb.2009.09.017.

Nanda JS, Saini AK, Munoz AM, Hinnebusch AG, Lorsch JR. 2013. Coordinated movements of eukaryotic translation initiation factors elF1, elF1A, and elF5 trigger phosphate release from elF2 in response to start codon recognition by the ribosomal preinitiation complex. Journal of Biological Chemistry 288:5316-5329. doi: 10. 1074/jbc.M112.440693.

Passmore LA, Schmeing TM, Maag D, Applefield DJ, Acker MG, Algire MA, Lorsch JR, Ramakrishnan V. 2007. The eukaryotic translation initiation factors elF1 and elF1A induce an open conformation of the 40S ribosome. Molecular Cell 26:41-50. doi: 10.1016/j.molcel.2007.03.018.

Pestova TV, Kolupaeva VG. 2002. The roles of individual eukaryotic translation initiation factors in ribosomal scanning and initiation codon selection. Genes \& Development 16:2906-2922. doi: 10.1101/gad.1020902.

Pisarev AV, Kolupaeva VG, Pisareva VP, Merrick WC, Hellen CU, Pestova TV. 2006. Specific functional interactions of nucleotides at key -3 and +4 positions flanking the initiation codon with components of the mammalian $48 \mathrm{~S}$ translation initiation complex. Genes \& Development 20:624-636. doi: 10.1101/gad.1397906.

Rabl J, Leibundgut M, Ataide SF, Haag A, Ban N. 2011. Crystal structure of the eukaryotic 40S ribosomal subunit in complex with initiation factor 1. Science 331:730-736. doi: 10.1126/science.1198308.

Reid GA, Schatz G. 1982. Import of proteins into mitochondria. Yeast cells grown in the presence of carbonyl cyanide $\mathrm{m}$-chlorophenylhydrazone accumulate massive amounts of some mitochondrial precursor polypeptides. The Journal of Biological Chemistry 257:13056-13061.

Saini AK, Nanda JS, Lorsch JR, Hinnebusch AG. 2010. Regulatory elements in elF1A control the fidelity of start codon selection by modulating tRNA(i)(Met) binding to the ribosome. Genes \& Development 24:97-110. doi: 10. 1101/gad.1871910.

Sharifulin D, Babaylova E, Kossinova O, Bartuli Y, Graifer D, Karpova G. 2013. Ribosomal protein S5e is implicated in translation initiation through its interaction with the $\mathrm{N}$-terminal domain of initiation factor elF2alpha. Chembiochem 14:2136-2143. doi: 10.1002/cbic.201300318.

Valasek L, Nielsen KH, Zhang F, Fekete CA, Hinnebusch AG. 2004. Interactions of eukaryotic translation initiation factor 3 (elF3) subunit NIP1/c with elF1 and elF5 promote preinitiation complex assembly and regulate start codon selection. Molecular and Cellular Biology 24:9437-9455. doi: 10.1128/MCB.24.21.9437-9455.2004.

Yoon HJ, Donahue TF. 1992. The sui1 suppressor locus in Saccharomyces cerevisiae encodes a translation factor that functions during tRNA ${ }_{i}{ }^{\text {Met }}$ recognition of the start codon. Molecular and Cellular Biology 12:248-260. 